\title{
Potential of high-resolution detection and retrieval of precipitation fields from X-band spaceborne synthetic aperture radar over land
}

\author{
F. S. Marzano ${ }^{1,2}$, S. Mori ${ }^{1,2}$, M. Chini ${ }^{3}$, L. Pulvirenti ${ }^{1}$, N. Pierdicca ${ }^{1}$, M. Montopoli ${ }^{2,5}$, and J. A. Weinman ${ }^{4}$ \\ ${ }^{1}$ Department of Information Engineering, Electronics and Telecommunications (DIET), Sapienza University of Rome, \\ Via Eudossiana 18, 00184 Rome, Italy \\ ${ }^{2}$ Center of Excellence CETEMPS, University of L'Aquila, L'Aquila, Italy \\ ${ }^{3}$ Istituto Nazionale di Geofisica e Vulcanologia, Rome, Italy \\ ${ }^{4}$ Department of Atmospheric Sciences, University of Washington, Seattle, Washington, USA \\ ${ }^{5}$ Department of Electric and Information Engineering, University of L'Aquila, L'Aquila, Italy
}

Received: 23 July 2010 - Published in Hydrol. Earth Syst. Sci. Discuss.: 29 September 2010

Revised: 19 January 2011 - Accepted: 8 February 2011 - Published: 11 March 2011

\begin{abstract}
X-band Synthetic Aperture Radars (X-SARs), able to image the Earth's surface at metric resolution, may provide a unique opportunity to measure rainfall over land with spatial resolution of about few hundred meters, due to the atmospheric moving-target degradation effects. This capability has become very appealing due to the recent launch of several X-SAR satellites, even though several remote sensing issues are still open. This work is devoted to: (i) explore the potential of X-band high-resolution detection and retrieval of rainfall fields from space using X-SAR signal backscattering amplitude and interferometric phase; (ii) evaluate the effects of spatial resolution degradation by precipitation and inhomogeneous beam filling when comparing to other satellite-based sensors. Our X-SAR analysis of precipitation effects has been carried out using both a TerraSAR-X (TSX) case study of Hurricane "Gustav" in 2008 over Mississippi (USA) and a COSMO-SkyMed (CSK) X-SAR case study of orographic rainfall over Central Italy in 2009. For the TSX case study the near-surface rain rate has been retrieved from the normalized radar cross section by means of a modified regression empirical algorithm (MREA). A relatively simple method to account for the geometric effect of X-SAR observation on estimated rainfall rate and firstorder volumetric effects has been developed and applied. The TSX-retrieved rain fields have been compared to those estimated from the Next Generation Weather Radar (NEXRAD) in Mobile (AL, USA). The rainfall detection capability of $\mathrm{X}$-SAR has been tested on the CSK case study using the
\end{abstract}

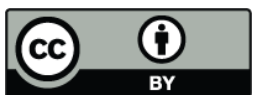

Correspondence to: F. S. Marzano (marzano@die.uniroma1.it) repeat-pass coherence response and qualitatively comparing its signature with ground-based Mt. Midia C-band radar in central Italy. A numerical simulator to represent the effect of the spatial resolution and the antenna pattern of TRMM satellite Precipitation Radar (PR) and Microwave Imager (TMI), using high-resolution TSX-retrieved rain images, has been also set up in order to evaluate the rainfall beam filling phenomenon. As expected, the spatial average can modify the statistics of the high-resolution precipitation fields, strongly reducing its dynamics in a way non-linearly dependent on the rain rate local average value.

\section{Introduction}

Nowadays global climate change is of increasing importance both for public opinion, the scientific community, and for its implications on the global economy and life of Earth's inhabitants. From this perspective, a better understanding of the physics of atmospheric processes is required to develop realistic numerical models for analysis and weather forecasting. Precipitation plays a fundamental role within the Earth water cycle and physical hydrology analyses (Dingman, 2002).

Current weather forecast models require high spatial resolution data to be assimilated (e.g., Masunaga et al., 2008). Spaceborne passive radiometers provides global spatial and temporal coverage of precipitation, but they are limited to a spatial resolution of tens of kilometers which tends to smooth convective rain cell and cluster signatures (e.g., Marzano et al., 2002; Tapiador et al., 2004). Moreover, their sensitivity to shallow stratiform rainfall over land is relatively low at lower microwave frequencies, whereas at higher

Published by Copernicus Publications on behalf of the European Geosciences Union. 
frequencies observations in presence of frozen hydrometeors are affected by many ambiguities (Bennartz and Petty, 2001). A well-known example of passive microwave radiometer is the TRMM Microwave Imager (TMI) aboard the Tropical Rainfall Measurement Mission (TRMM) satellite. Higher resolution could be obtained by infrared radiometers, but infrared radiance is almost saturated by the presence of precipitating clouds within the observed scene (Tapiador et al., 2004). Spaceborne radar operating at Ku-band (i.e. about $2 \mathrm{~cm}$ wavelength) can avoid some of these limitations (Marzano et al., 2002). An example of such a radar is the Precipitation Radar (PR) aboard the TRMM satellite. It has provided unprecedented precipitation measurements over land (Iguchi et al., 2000), but it may underestimate the intensity of shallow precipitation or that from rain cells smaller than $4 \mathrm{~km}$ (Durden et al., 1998).

The high spatial resolution of spaceborne synthetic aperture radars (SARs) operating at X-band (i.e., about $3 \mathrm{~cm}$ wavelength) might provide new insights into the structure of precipitating clouds, including the observation of small precipitation cells at micro-alpha scale between 0.2 and $2 \mathrm{~km}$ (Jameson et al., 1997; Melsheimer et al., 1998). The possibility of observing rain cells by means of such sensors have been reported by several authors (e.g. Weinman and Marzano, 2008; Danklmayer et al., 2009; Chandrasekar and Fritz, 2009). Indeed, the exploitation of X-SAR observations for quantitative precipitation retrieval is far from being fully assessed and demonstrated. First of all, the nominal spatial resolution of SAR (on the order of meters) is degraded by the turbulent motion of the falling hydrometeors (on the order of hundreds of meters) due to the broadening of the Dopplerfrequency spectrum with respect to filters used in fixed-target imaging (Atlas and Moore, 1987). Secondly, the slant observation geometry makes the X-SAR atmospheric signature interpretation fairly cumbersome (Marzano and Weinman, 2008). The surface backscattering signal amplitude is mainly affected by rain slant-path attenuation, but it may also depend on the volumetric backscattering of ice hydrometeors within oblique resolution bins (e.g., Weinman and Marzano, 2008; Danklmayer et al., 2009). The XSAR received signal phase is also influenced by water vapor and liquid hydrometeor distribution through their effect on the atmospheric refractivity and related path delay (Quegan and Lamont, 1986). Finally, $\mathrm{X}$-SAR observations is nowadays severely limited by the low temporal resolution (or repetition period) due to low Earth orbit (between 500 and $600 \mathrm{~km}$ height), limited sensor swath (typically less than $200 \mathrm{~km}$ ) and limited sensor duty cycle per orbit (typically less than 15\%). Nevertheless, even if X-SAR quantitative rainfall measurements is still at an early stage, its potential for precipitation remote sensing is very appealing, due to the retrieved high spatial resolution and the possibility to access to remote regions, non-instrumented areas, ocean surfaces and mountainous regions.

The current interest in spaceborne X-SAR measurements is demonstrated by several mission planned or in advanced deployment such as TerraSAR-X (TSX), launched on 2007 by the Deutsches zentrum fur Luft und Raumfahrt (DLR) (Buckreuss et al., 2003), and the Constellation of Small Satellites for Mediterranean basin Observations (COSMOSkyMed or CSK), developed by the Agenzia Spaziale Italiana (ASI) (Coletta et al., 2007). Three of these CSK satellites are already aloft, and the fourth will be launched within 2010. This technological scenario, destined to be further expanded, represents a great jump since the launch of the SIRC/SAR-X mission in 1994, which provided the first X-SAR observations from space (e.g., Jameson et al., 1997).

In previous studies, we have developed theoretical and numerical models of the spaceborne X-SAR response to precipitation systems, characterized by liquid and frozen hydrometeor spatial distributions (Weinman and Marzano, 2008; Marzano and Weinman, 2008; Weinman et al., 2009; Marzano et al., 2009). There are still open issues related to further explore the potential of X-band high-resolution detection and retrieval of rainfall fields by exploiting X-SAR received signal co-polar amplitude and phase, and to evaluate the effects of spatial resolution degradation and inhomogeneous beam filling by precipitation. Near-surface rain rate can be retrieved from the X-SAR backscatter coefficient using an empirically-based parametric regression technique, but both geometrical and volumetric effects need to be taken into account in a more effective way. Rainfall detection capability of X-SAR may be also tested using the repeat-pass coherence response to isolate the possible correlation degradation due to the precipitation field.

This paper is organized as follows. In Sect. 2, we will introduce: (i) TSX and CSK systems together with the basics of the X-SAR response interpretation; (ii) TMI and PR sensor specifications; (iii) weather radars used as ground "truth" data. In Sect. 3 two case studies will be analyzed and discussed. Within the TSX case study an improved empiricallytuned formula to retrieve rainfall rates from X-SAR signal attenuation will be presented. Repeat-pass coherence maps will be discussed to detect rainfall signature over land in central Italy. In Sect. 4 we will perform a quantitative analysis of spatial resolution degradation and non-uniform beam filling effects on rain rate estimation when using spaceborne instruments at a resolution lower than the X-SAR one. In Sect. 5, conclusions will be drawn.

\section{Available space-based and ground-based data}

Data sources and features will be briefly discussed together with the satellite-based and ground-based imagery available for the considered case studies.

\subsection{X-SAR satellite data}

The TerraSAR-X is an Earth observation satellite from DLR in partnership with EADS Astrium $\mathrm{GmbH}$, designed to 
provide high-quality topographic information for commercial and scientific applications. The TerraSAR-X instrument is a 384-element active phased array X-Band system with a centre frequency of $9.65 \mathrm{GHz}$ (Buckreuss et al., 2003). The TSX satellite circles the Earth in a nearly polar orbit at approximately $514 \mathrm{~km}$ altitude with a flight speed of $7.6 \mathrm{~km} \mathrm{~s}^{-1}$, and with a repetition rate of 11 days (due to electronic pointing agility, a 2.5-day revisit time can be achieved). Four modes of operations are foreseen, both at single polarization and at dual polarization, supporting both co-polar observations (HH, VV) and cross-polar ones (HV, $\mathrm{VH})$, with an incident angle $\theta$ between $20^{\circ}$ and $55^{\circ}$. The TSX acquires digital radar images, with resolution up to $1 \mathrm{~m}$ at the Earth's surface. When the target moves, such as precipitation (characterized by the advection of a turbulent flow of size-dependent falling particles), the X-SAR nominal resolution and geolocation could be significantly affected (Atlas and Moore, 1987; Weinman et al., 2009). In typical rainfall situations the along-track resolution may degrade to $\sim 135 \mathrm{~m}$ and the cross-track one to $\sim 676 \mathrm{~m}$.

The COSMO-SkyMed (COnstellation of small Satellites for the Mediterranean basin Observation) is an Earth observation satellite system, funded by the Italian Ministry of Research and Ministry of Defence and conducted by the Italian Space Agency (ASI), intended for both military and civilian use (Covello et al., 2010). The space segment of the CSK system includes four medium-sized satellites equipped with synthetic aperture radar (SAR) sensors with global coverage of the planet. Observations of an area of interest will be repeated several times a day in all-weather conditions. The four satellites are planned for most sun-synchronous polar orbits, phased at $90^{\circ}$ and at an altitude of $619 \mathrm{~km}$ with an orbit period of $97 \mathrm{~min}$. The expected operating life of each satellite is estimated in 5 years. The first satellite COSMO-1 was launched at 22:34 UTC, on 8 June 2007, whereas COSMO2 at 02:31:42 UTC on 9 December 2007 and COSMO-3 at 02:38 UTC on 25 October 2008, with COSMO-4 expected in 2010. Four modes of operations are foreseen with different resolution and coverage (i.e., Spotlight, Stripmap, Polarimetric, ScanSAR); those at single polarization support both copolar observations (HH, VV) and cross-polar ones (HV, VH), whereas the Polarimetric mode provides dual polarized radar returns. Incident angles $\theta$ is between $20^{\circ}$ and $55^{\circ}$ and spatial resolution goes from $100 \mathrm{~m}$ for the ScanSAR mode down to $1 \mathrm{~m}$ for the Spotlight mode.

\subsection{TRMM satellite data}

The Tropical Rainfall Measuring Mission (TRMM) is a joint mission between the USA National Aeronautics and Space Administration (NASA) and the Japan Aerospace eXploration Agency (JAXA). The objectives of TRMM are to measure rainfall and energy (i.e., latent heat of condensation) exchange of tropical and subtropical regions of the world (Kummerow et al., 1998). The primary rainfall instruments on TRMM are the TRMM Microwave Imager (TMI), the Precipitation Radar (PR), and the Visible and Infrared Radiometer System (VIRS). The space segment of TRMM is a satellite in a $350-\mathrm{km}$ circular orbit with a $35^{\circ}$ inclination angle.

For our analysis we are mainly interested in the microwave instruments. The TMI is a nine-channel passive microwave radiometer at $10.65 \mathrm{GHz}$ (Vertical $V$ and horizontal $H$ polarization), $19.35 \mathrm{GHz}(V$ and $H), 21.3 \mathrm{GHz}(V), 37.0 \mathrm{GHz}(V$ and $H$ ), $85.5 \mathrm{GHz}(V$ and $H$ ) which grant a beam effective field-of-view (EFOV) of $63 \times 37,30 \times 18,23 \times 18,16 \times 9$ and $7 \times 5 \mathrm{~km}^{2}$, respectively. EFOV is the effective area swept by the antenna beam during the integration time. The PR is a radar consisting of a 128-element active phased array system operating at $13.8 \mathrm{GHz}$. Its swath width is $215 \mathrm{~km}$, the horizontal resolution (at nadir) is $4.3 \mathrm{~km}$ and the range resolution is $0.25 \mathrm{~km}$. It observes along the cross-track direction, within a scan angle of $\pm 17^{\circ}$.

\subsection{Ground-based weather radar}

Due to their spatial and temporal coverage, operational ground-based Weather Radars (WRs) offer good opportunities to compare space-borne X-SAR imagery with precipitation ground-based measurements. Matching satellite and ground measurements is a difficult task due to spaceborne XSAR frequency characteristics, the limited orbit duty-cycle, the relative small swath and the high spatial resolution.

The Next Generation Weather Radar (NEXRAD) network assures significant coverage of Conterminous United States (CONUS) with an acquisition time of the order of 5 min. This network is composed of Doppler radars designated Weather Surveillance Radar 1988 Doppler (WSR88D) (Fulton et al., 1998) which operates at S-Band horizontal polarization, and since mid 2008 it has been providing PPI data with a sample size of $250 \mathrm{~m}$ in range and $0.5^{\circ}$ in azimuth ("Super-Resolution"). WSR-88D measurements are corrected for artifacts such as beam blockage, anomalous propagation and profile inhomogeneity, but residual errors may affect the estimated rainfall fields.

Data from the C-band Mt. Midia radar in central Italy have been also used (Picciotti et al., 2008). The Mt. Midia singlepolarization weather radar is located at about $1700 \mathrm{~m}$ with an antenna beamwidth of $1.6^{\circ}$ and a robust data quality control. Measurements are taken every $15 \mathrm{~min}$ with a spatial radial resolution of $250 \mathrm{~m}$ and azimuth angular resolution of $0.5^{\circ}$. Four elevation angles are usually acquired during an entire volume scan.

Rain rate $R\left[\mathrm{~mm} \mathrm{~h}^{-1}\right]$ measurements are obtained from WR reflectivity $Z \mathrm{~mm}^{6} \mathrm{~m}^{-3}$ using a $Z-R$ relation similar to Marshall-Palmer: the standard NEXRAD relation is $Z=300 \cdot R^{1.4}$ (Fulton et al., 1998), whereas for the Mt. Midia it is locally calibrated through rain-gauge networks (Picciotti et al., 2008). This kind of measurements may be subject to large systematic and random errors mainly due to the 
variability of drop size distributions which can be partially estimated only by using polarimetric radar systems (Marzano et al., 2008; Ryzhkov et al., 2005), so that typical errors in the estimate of rainfall may exceed 50\% (Fulton et al., 1998).

\section{Case studies}

With respect to a nadir-looking radar, the radar resolution volume of a side-looking radar, such as a SAR, is always represented by a slant slice of the atmosphere including the ground-range surface pixel. To model the X-SAR received Normalized Radar Cross Section (NRCS) in the presence of precipitation, we need to take into account both the two-way attenuation of surface NRCS due to rainfall and the atmospheric volume reflectivity. The NRCS for each cross-track pixel of the observed scene can be formally described by the sum of two terms (e.g., Weinman and Marzano, 2008):

$\sigma_{\mathrm{SAR}}(x)=\sigma_{\mathrm{srf}}(x)+\sigma_{\mathrm{vol}}(x)$

with

$$
\left\{\begin{array}{l}
\sigma_{\mathrm{srf}}(x)=\sigma^{0}(x) \exp \left(-2 \int_{0}^{\infty} k[x(z)] d z / \cos \theta\right) \\
\sigma_{\mathrm{vol}}(x)=\int_{0}^{\infty} \eta[x(z)] \exp \left(-2 \int_{z}^{\infty} k\left[x^{\prime}\left(z^{\prime}\right)\right] d z^{\prime} / \cos \theta\right) d z
\end{array}\right.
$$

where $x$ is the cross-track ground coordinate, $z$ the altitude, $\sigma_{\text {srf }}$ is the co-polar backscattering NRCS from the surface, attenuated by the two-way path through the precipitating atmosphere, $\sigma_{\mathrm{vol}}$ is the volume co-polar backscattering NRCS, due to the ice, melted and liquid hydrometeor reflectivity weighted by the two-way path attenuation through the intervening precipitation, $\sigma^{0}$ is the surface backscattering coefficient, $k$ is the co-polar specific attenuation, $\eta$ the co-polar volumetric reflectivity, and $\theta$ is the incidence angle (with respect to the surface normal).

Two case studies are considered here, related to rainfall observations from TSX and CSK platforms. These case studies are introduced to show how X-SAR backscattering coefficient amplitude is suitable for rainfall content retrieval, whereas the use of the X-SAR interferometric phase may be exploited for precipitation detection.

\subsection{Hurricane "Gustav" observed from TSX, TRMM and WR}

For our analysis we have considered a case study over Mississippi centered at about $30.5^{\circ} \mathrm{N} \times 89.5^{\circ} \mathrm{W}$, acquired by TerraSAR-X on 2 September 2008 12:00 UTC (from 11:58:44 to 11:59:06 UTC). The same scene was observed by the ground-based NEXRAD weather radar WR), located in Mobile (AL) with a time difference of about 1 min (acquisition started at 11:59:44 UTC). For this case study, no TSX "background image" was available to show the same scene without rainfall in order to better separate the contribution of the surface background. The selected area was observed by
TRMM at about 15:30 UTC; from the radio-sounding performed in Birmingham (AL) at 12:00 UTC, we have estimated that the freezing level height was about $4.5 \mathrm{~km}$. The selected case study refers to the passage of Hurricane "Gustav" over Louisiana and Mississippi northwestward, moving at an average velocity of $24 \mathrm{~km} \mathrm{~h}^{-1}$, delivering torrential rains to the central gulf coast of the USA (e.g. Larto Lake, LA, reported a rainfall total accumulation of $533.4 \mathrm{~mm}$ ).

TSX data were available in ScanSAR horizontallypolarized mode and obtained as Level-1b Multi-look Ground Detected (MGD) format (Buckreuss et al., 2003). The MGD format presents a reduced speckle, due to the six-looking averaging, and is obtained by a simple polynomial slant-toground projection in range using WGS84 ellipsoid and an average constant terrain height; the choice to avoid automatic terrain corrections reduces the circumstance of removing rainfall signatures being the latter potentially confused with topographic effects. The resolution of TSX ScanSAR image on ground is about $18 \times 18 \mathrm{~m}^{2}$. TSX data have been calibrated using the annotation and geo-location data set provided with the TerraSAR-X Level-1b package. Co-located NEXRAD WR data were available in terms of Level-II horizontally-polarized radar reflectivity factor $Z$ with a spatial resolution of about $0.25 \mathrm{~km}$ in range and $0.5^{\circ}$ in azimuth and nominal coverage radius of about $209 \mathrm{~km}$.

Figure 1 shows the ground-based NEXRAD National Radar Reflectivity mosaic at 12:00 UTC (corresponding to TSX observation). The spiral cyclonic signature of the Hurricane "Gustav" is quite evident and a significant enhancement of reflectivity over Louisiana and Mississippi is also noted. In the next hours NEXRAD imagery showed a slight increase of the hurricane activity with a relative small shift northwestward in the 15:00 UTC NEXRAD image.

Figure 2 shows the available TRMM satellite observations whose time sampling is dictated by the inter-tropical low-Earth orbit (e.g., Kummerow et al., 1998). The figure shows the acquired horizontally-polarized TMI brightness temperatures (TB) at $37 \mathrm{GHz}$ and $85.5 \mathrm{GHz}$ (obtained from TRMM 1B11 product). The TMI image swath is about $760 \mathrm{~km}$ wide, the ground resolution about $16 \times 9 \mathrm{~km}^{2}$ at $37 \mathrm{GHz}$ and $7 \times 5 \mathrm{~km}^{2}$ at $85.5 \mathrm{GHz}$. Data were acquired at 15:30 UTC, three hours and half after the TSX pass, so that a direct intercomparison between TRMM and TSX is not possible. Nevertheless, it is useful to take Fig. 2 as example of the current capabilities of MW radiometric and radar spaceborne imagers, as the spatial resolution issue will be dealt in the next section. The hurricane signature is quite evident, but the impact of the different spatial resolution between the two radiometric channels is also striking. Figure 2 also illustrates the PR reflectivity factor (dBZ) at $14 \mathrm{GHz}$ and closest to the surface for both the "normal sampled" range bin 75 and the "rain oversampled" range bin 16 (as obtained from TRMM 1C21 product). The PR swath is $220 \mathrm{~km}$ for the "normal sampled" product, but it is reduced for the "rain oversampled" one due to oversampling; the height resolution is 


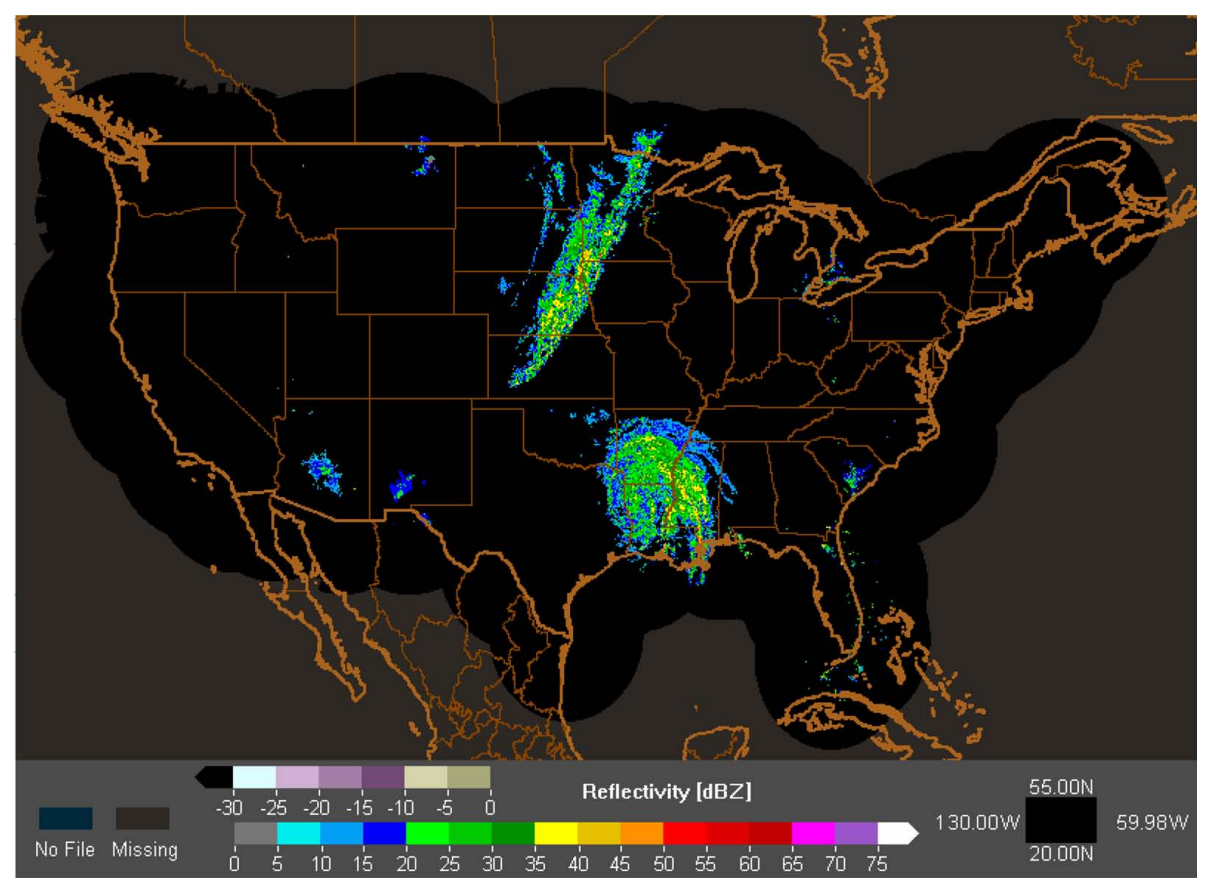

Fig. 1. NEXRAD National Radar Reflectivity mosaic (in dBZ) on 2 September 2008 at 12:00 UTC. We can observe the signature of Hurricane "Gustav" covering Louisiana, Mississippi and Arkansas.

about $0.25 \mathrm{~km}$. The "rain oversampled" product aims to register the detailed vertical profile of the rain. Figure 2 shows that the spiral tails of the hurricane are detectable with a moderate spatial resolution, but only the combination with TMI can provide the general features of the hurricane due to the relatively smaller swath. The latter argument, indeed, applies to most active microwave sensors whose scanning capabilities are usually limited with respect to passive ones.

Figure 3 shows the Plan Position Indicator (PPI) reflectivity map (dBZ), acquired at $0.86^{\circ}$ elevation angle by the SBand NEXRAD WR of Mobile (AL), indicated as "KMOB" in figure. This map shows a geographical zoom of Fig. 1. The indicated elevation angle has been used as representative of near-surface rainfall field. Enclosed within the white rectangle is the quick-look of the TSX selected scene (about $\left.154 \times 105 \mathrm{~km}^{2}\right)$; the quick-look resolution is $0.1 \mathrm{~km}$. The feature similarity between TSX and WR maps, especially within the hurricane rain band, is noticeable; moreover we can qualitatively appreciate the higher spatial resolution of TSX imagery with respect to TRMM-PR and TRMM-TMI one, as shown in Fig. 2

A pre-processing procedure is necessary to compare TSX and WR data, due to differences in their spatial coverage and resolution. Both images have been co-registered and degraded through an appropriate moving-average filter at the resolution of about $500 \mathrm{~m}$ and down-sampled at about $500 \mathrm{~m}$. Spatial features are consistent with the effective resolution obtainable from X-SAR processing techniques applied to incoherent moving targets, such as precipitation (e.g., Marzano et al., 2010). Finally, TSX and WR have been projected adopting an Universal Transverse Mercator (UTM) coordinate system.

Figure 4 shows the obtained co-registered maps, where the rain pattern is evident in both images with detailed spatial features. The maximum intensity of the hurricane "Gustav" precipitation can be deduced from WR reflectivity measurements; $Z$ maximum is about $59.1 \mathrm{dBZ}$, denoting torrential convective rainfall probably mixed to some hail (Ryzhkov et al., 2005). The same image also shows a significant negative correlation between TSX retrieved Normalized Radar Cross Section (NRCS) $\sigma_{\text {SAR }}$ and WR reflectivity $Z$, demonstrating that the first tends to decrease whereas the second increases, mainly due to the increase of the two-way rain path attenuation. This behavior is well described by current numerical models of X-SAR response, as summarized in Eq. (1) (e.g., Marzano and Weinman, 2008).

The considered case study was first analyzed in Marzano et al. (2010). In the latter paper, a regressive empirical algorithm (REA) for X-SAR rainfall retrieval was applied, having the following power-law expression:

$$
\begin{aligned}
\hat{R}_{\mathrm{REA}}(x) & =a_{\mathrm{e}}\left[\sigma_{\mathrm{dB}}^{0}(x)-\sigma_{\mathrm{SARdB}}(x)\right]^{b_{\mathrm{e}}} \\
& =a_{\mathrm{e}} \Delta \sigma_{\mathrm{SARdB}}^{b_{\mathrm{e}}}(x)
\end{aligned}
$$

where $x$ is a point on the cross-track direction, $\sigma_{\mathrm{dB}}^{0}(\mathrm{~dB})$ is the background NRCS, $\sigma_{\mathrm{SARdB}}(\mathrm{dB})$ is the TSX retrieved NRCS such that $\Delta \sigma_{\mathrm{SARdB}}=\sigma_{\mathrm{dB}}^{0}-\sigma_{\mathrm{SARdB}}$ is positively defined. The 


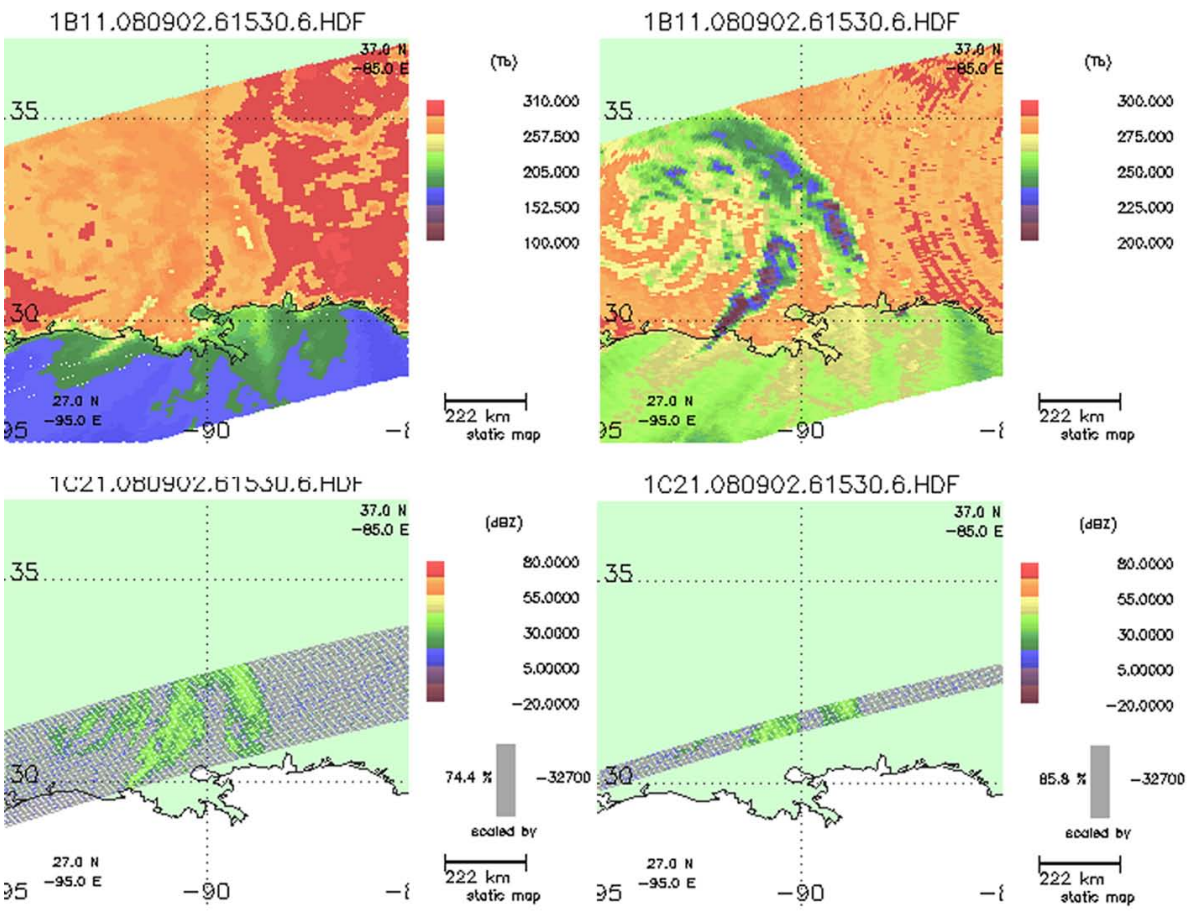

Fig. 2. TRMM observations over the selected case study of Louisiana and Mississippi, 2 September 2008 at 15:30 UTC. Top panels: TRMM 1B11 brightness temperature (TB) product relative to TMI channel 7 ( $37 \mathrm{GHz}$ horizontal polarization, left), beam effective field-of-view (EFOV) of $16 \times 9 \mathrm{~km}^{2}$, and TMI channel $9\left(85.5 \mathrm{GHz}\right.$ horizontal polarization, right) with a main-beam EFOV of $7 \times 5 \mathrm{~km}{ }^{2}$. The cyclonic cell indicated in Fig. 1 is near-fully imaged. Bottom panels: the TRMM 1C21 radar reflectivity (dBZ) product, relative to PR normal sample (left) range bin 75, and PR rain oversample (right), range bin 16. Note that the PR swath is $220 \mathrm{~km}$ wide (reduced in the oversampled product) and the range resolution is $0.25 \mathrm{~km}$; TMI swath is $760 \mathrm{~km}$ wide. This image has been realized by using NASA/GSFC PPS Orbit Viewer.

criterion $\Delta \sigma_{\mathrm{SARdB}}>0$ is assumed to be a rain detection rule and its accuracy strongly depends on the knowledge of background $\sigma_{\mathrm{dB}}^{0}$. In Eq. (3) $R_{\mathrm{REA}}$ is the estimated rain rate $\left(\mathrm{mm} \mathrm{h}^{-1}\right) ; a_{\mathrm{e}}$ and $b_{\mathrm{e}}$ are two empirical parameters that we have determined to be respectively 3.37 and 1.55 supposing an average background $\sigma_{\mathrm{dB}}^{0}$ equal to $-7.9(\mathrm{~dB})$, obtained from the mean of the surrounding non-raining pixels in the same X-SAR image with a standard deviation of about $1 \mathrm{~dB}$. The coefficients in Eq. (3) could be obtained, in principle, by using the physical relation between specific attenuation and rainfall intensity (derivable from the spatial distribution of the particle size distribution, obtained by means of a polarimetric WR) when a slant observation geometry is considered, as partly shown by Marzano et al. (2010). The X-SAR side-viewing geometry introduces a characteristic pattern of the observed NRCS due to the increasing attenuation path as the incident radar ray moves within the precipitation cell from near to far ranges (e.g., Weinman and Marzano, 2008). This deformation is such that the X-SAR tends to underestimate rainfall intensity at the near-range edges and to overestimate it at the far-range edges with a fictitious broadening of the rainfall footprint. In order to take these geometrical effects into account, we have modified the retrieval formula
Eq. (3) by introducing a factor $f_{\mathrm{G}}(x)$ that accounts for the location of a pixel with respect to the edge cell. Moreover, for heavy rainfall intensity the model of Eq. (3) tends to underestimate the volumetric backscattering contribution $\sigma_{\mathrm{vol}}$, as in Eq. (1); this effect may be partially corrected by a first-order approach. The new formulation of the X-SAR modified regressive empirical algorithm (MREA), briefly derived in the Appendix, becomes:

$$
\begin{aligned}
& \hat{R}_{\text {MREA }}(x)= \\
& \quad= \begin{cases}{\left[\frac{\Delta \sigma_{\mathrm{SARdB}}(x)+b_{\mathrm{v}} \Delta \sigma_{\mathrm{SARdB}}^{c_{\mathrm{V}}}(x)}{a}\right]^{1 / b}\left[\frac{1}{\left(x-x_{0}\right)}\right]^{c_{\mathrm{e}}}} & \begin{array}{l}
x_{0}+\varepsilon \leq x \leq x_{0}+w \\
0
\end{array}\end{cases}
\end{aligned}
$$

where the parameters $a, b, b_{\mathrm{v}}, c_{\mathrm{v}}$ and $c_{\mathrm{e}}$ are regressive coefficients, obtained by least-square regression analysis using the TSX and WR data from hurricane Gustav; they have been estimated, respectively, $0.0089,2.4595,0.1216,3.8979$ and -0.0230 . The parameter $\varepsilon$ in Eq. (4) is introduced to prevent the singularity in $x=x_{0}$ and is usually equal to few pixels in the ground range. The previous Eq. (4) applies to all the TSX pixels where $\Delta \sigma_{\mathrm{SARdB}} \geq 1$ taking into account the $\sigma_{\mathrm{dB}}^{0}$ background uncertainty. The parameter $x_{0}$ is the near-range edge of the rain cloud with $w$ its cross-track width, derived 


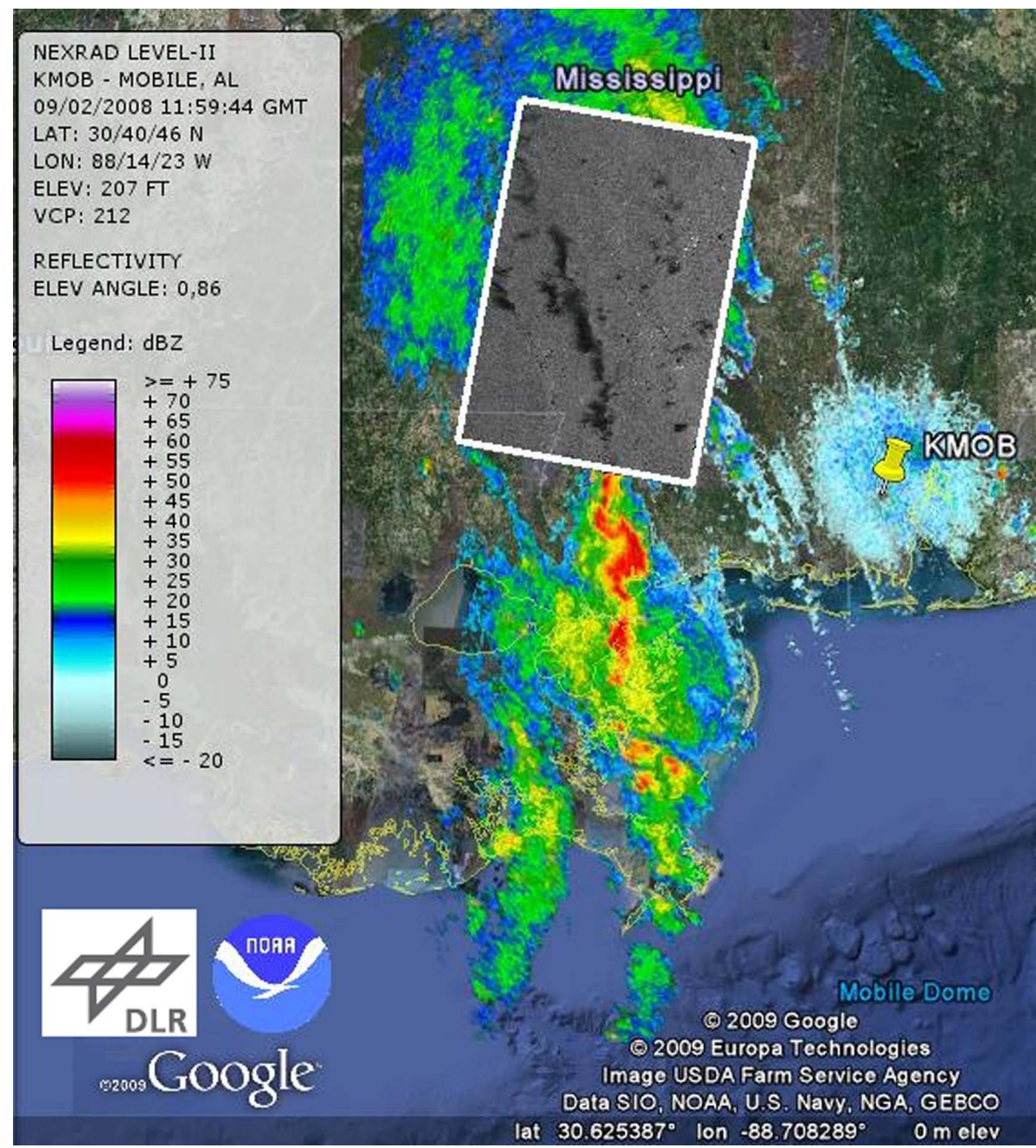

Fig. 3. Geographic representation of the NEXRAD reflectivity plan-position-indicator (PPI, in dBZ) at $0.86^{\circ}$ elevation angle, acquired by the S-band Weather Radar (WR) near Mobile (AL, KMOB in figure) on 2 September 2008, at 12:00 UTC. The white bordered box, centered around $30.5^{\circ} \mathrm{N} \times 89.5^{\circ} \mathrm{W}$, represents the scene of interest acquired by TerraSAR-X (TSX) around the same time: within the box a $100 \mathrm{~m}$ resolution TSX quicklook is placed in arbitrary units. This image has been produced by using NOAA NCDC Weather and Climate Toolkit, TSX preview data and Google Earth software tools.

from measured NRCS cross-track curve such that $\Delta \sigma_{\mathrm{SAR}}$ intersects the threshold value. Note that in order to empirically tune Eq. (4) with ground reference, WR rain rate estimates have been obtained by inverting the $Z-R$ relation:

$$
\hat{R}_{\mathrm{WR}}(x)=\left[Z(x) / a_{\mathrm{r}}\right]^{1 / b_{\mathrm{r}}}
$$

where $Z$ is the measured reflectivity factor $\left(\mathrm{mm}^{6} \cdot \mathrm{m}^{-3}\right)$, $R_{\mathrm{WR}}$ is the estimated rain rate $(\mathrm{mm} / \mathrm{h}), a_{\mathrm{r}}=300$ and $b_{\mathrm{r}}=1.4$, in case of a NEXRAD standard relation (note that in Marzano et al., 2010, the Marshall-Palmer $Z-R$ was used instead).

Figure 5 shows the different maps obtained by the two methods REA and MREA, given in Eqs. (3) and (4), respectively. The pattern of the retrieved rainfall is very similar, but looking at the edges of the precipitation field the geometrical correction tends to enhance the rain values at closer range and reduces its values at farther range near the rainfall cell edges. A quantitative analysis of the error with respect to WR-based estimates shows that for REA and MREA retrieval algorithms, the correlation coefficient is of 0.74 and 0.75 , the error biases of 0.64 and $-0.66 \mathrm{~mm} \mathrm{~h}^{-1}$, the root mean square errors (RMSEs) of 24.12 and $22.28 \mathrm{~mm} \mathrm{~h}^{-1}$ and the Fractional RMSE (FRMSE, defined as the ratio between estimation RMSE and root-mean-square value of $R_{\mathrm{WR}}$ over the whole dataset) of 1.06 and 0.98 , respectively. The mean difference (in absolute value) between REA and MREA is $1.30 \mathrm{~mm} \mathrm{~h}^{-1}$, its standard deviation $7.71 \mathrm{~mm} \mathrm{~h}^{-1}$, RMSE $7.82 \mathrm{~mm} \mathrm{~h}^{-1}$, whereas FRMSE is 0.21 and the correlation coefficient is 0.98 . These results are summarized in Table 1 . 

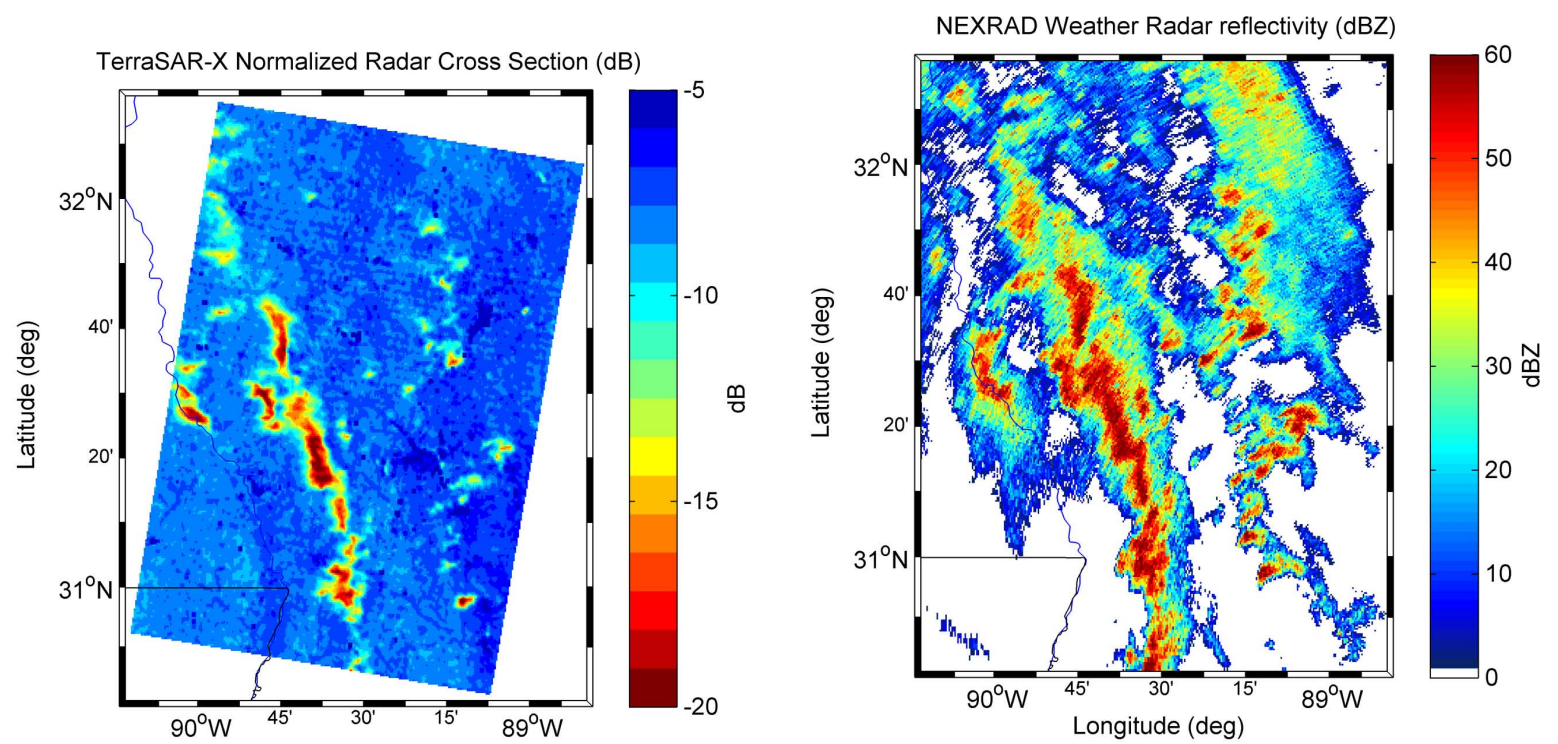

Fig. 4. Left: TSX calibrated NRCS (dB) for the selected case study in Fig. 1. TSX data have been filtered and resampled to about $0.5 \mathrm{~km}$ resolution. Right: co-registered NEXRAD reflectivity factor $Z$ PPI (dBZ) at $0.86^{\circ}$ elevation angle at the same resolution of $0.5 \mathrm{~km}$.
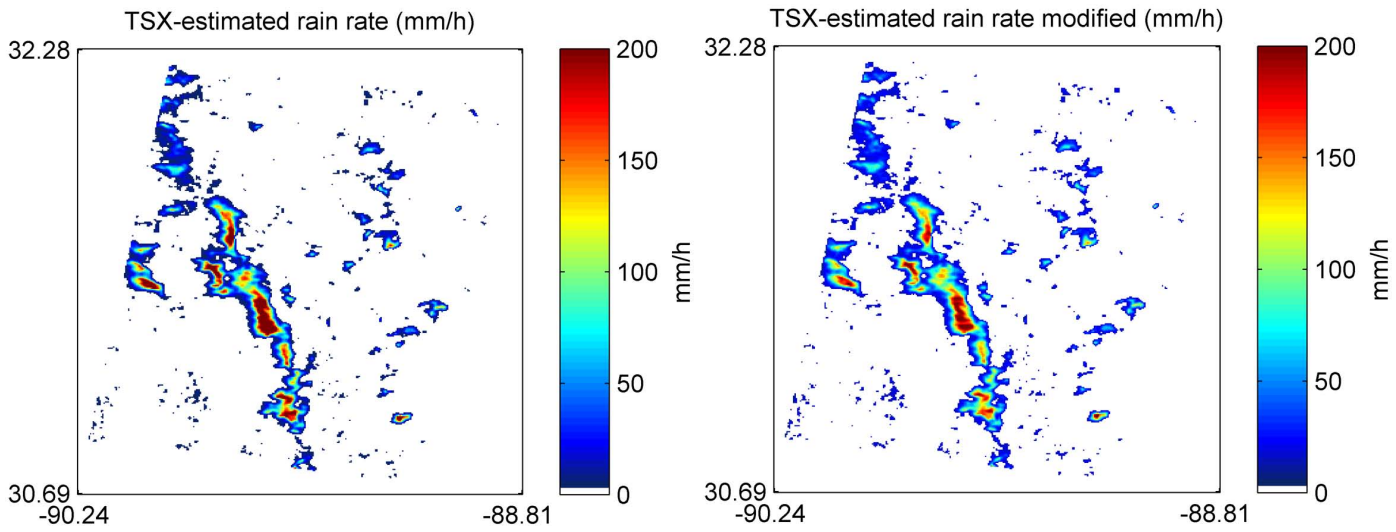

Fig. 5. Left: TSX-estimated rain rate according to the regressive empirical algorithm (REA) approach of Eq. (3), as suggested in Marzano et al. (2010), using TSX data of Fig. 4. Right: TSX-estimated rain rate according to the modified regressive empirical algorithm (MREA), given in Eq. (4). For graphical purposes scales are equally saturated at $200 \mathrm{~mm} \mathrm{~h}^{-1}$, even though rain-rate values can be higher than $300 \mathrm{~mm} \mathrm{~h}^{-1}$ (see text).

\subsection{Orographic precipitation observed from CSK and WR}

A case study in Central Italy has been selected by accessing the archive of Mt. Midia C-band WR data (Picciotti et al., 2008), occurred on 18 May 2009, 17:15 UTC in a region close to city of L'Aquila (Italy). The covered area is affected by both western and eastern fronts coming from the Atlantic Ocean and Siberia, respectively. Orographic precipitation plays a crucial role due to the Appennine range (up to nearly $3000 \mathrm{~m}$ ). Mesoscale Convective Systems (MCS) may develop within the area with cluster organized cells during late summer and early fall, very often causing localized hailstorms.

Whilst in the previous case study we have concentrated on the analysis of the backscattering amplitude coefficient, in this case we have exploited the CSK multi-platform constellation to evaluate the temporal interferometric response of X-SAR measurements to rainfall areas. It is well known in literature that the atmosphere produces phase delay on the SAR signal, which is composed by two main contributions, ionospheric and tropospheric (e.g., Quegan and Lamont, 1986). The refractivity of air introduces uncertainties in the time of arrival of the microwave signal due to the bending 
Table 1. Error analysis of the difference between the rain fields of WR and those at obtained with REA in Eq. (3) and MREA in Eq. (4). Difference between REA and MREA are given in terms of statistical moments.

\begin{tabular}{lrrr}
\hline & WR-REA & WR-MREA & REA-MREA \\
\hline${\text { Error Bias }\left[\mathrm{mm} \mathrm{h}^{-1} \text { ] }\right.}_{\text {Dev. Standard }}$ & 0.64 & -0.66 & -1.30 \\
RMSE $\left[\mathrm{mm} \mathrm{h}^{-1}\right.$ ] & 24.11 & 22.27 & 7.71 \\
FRMSE & 24.12 & 22.28 & 7.82 \\
Correlation & 1.06 & 0.98 & 0.21 \\
& 0.74 & 0.75 & 0.98 \\
\hline
\end{tabular}

and slowing along the propagation path. The ionospheric effect is inversely proportional to the square of the radar frequency in the microwave part of the spectrum, so that lower frequencies could be more affected by the path delay, particularly near the geomagnetic equator and poles (Massonnet and Feigl, 1998). Conversely, at microwave frequencies the tropospheric unpredictable effect on path delay is essentially due to water vapor content and cloud hydrometeors, the former being spectrally non-dispersive, whereas the latter is strongly frequency-dependent (and fairly significant at frequencies above $\mathrm{C}$ band). The phase delay in the clear troposphere consists of hydrostatic and wet components. Although the latter is smaller in magnitude (about $30 \mathrm{~cm}$ on average at frequencies less than $10 \mathrm{GHz}$ ), it is far more spatially variable than the hydrostatic and ionospheric delays. In fact, changes in the distribution of water vapor are associated with clouds, convection, and storms. In addition, variations resulting from orographic, frontal, coastal, and seasonal gradients may be present.

In the presence of hydrometeors (such as fog, rain, hail, snow, and graupel) there is a contribution to the path delay. Sohleim et al. (1999) computed path delays induced by rain, hail and snow at the Global Positioning System (GPS) carrier frequencies, obtaining a path delay of about $6 \mathrm{~mm}$ for light rain of $20 \mathrm{~mm} \mathrm{~h}^{-1}$ (delay of $2 \mathrm{~mm} \mathrm{~km}^{-1}$ for a nadir rain scale height of $3 \mathrm{~km}$ ) up to $9 \mathrm{~cm}$ for heavy rain of $200 \mathrm{~mm} \mathrm{~h}^{-1}$ (delay of $15 \mathrm{~mm} \mathrm{~km}^{-1}$ at L2 carrier for a rain scale height of $6 \mathrm{~km}$ ). Based on analysis of two X-SAR interferograms, Moisseev and Hanssen (2003) showed that precipitation caused an enhanced signal delay, but the most probable explanation of this effect was an increase in water vapor concentration due to partial evaporation of raindrops. Simulations at $\mathrm{C}$ band and $\mathrm{X}$ band show that for $100 \mathrm{~mm} \mathrm{~h}^{-1}$ and $5 \mathrm{~km}$ nadir rain- scale height the two-way range delay may be about $5 \mathrm{~cm}$, whereas for $10 \mathrm{~mm} \mathrm{~h}^{-1}$ and $5 \mathrm{~km}$ nadir rain path the two-way range delay is about $1 \mathrm{~cm}$ (Matricciani, 2009). Finally, if the hydrometeor concentration is such to produce a fluctuation of the refractive index, the latter could cause a random phase error in the SAR signal, affecting the signal coherence (Quegan and Lamont, 1986). Stemming from the above mentioned issues, the X-band SAR data from COSMO-SkyMed mission and the interferometric coherence seem to be a way for detecting rain from a high resolution spaceborne radar imagery.

Concerning the selected raining event, four COSMOSkyMed images, acquired on four different days (around 17:15 UTC) have been used. The acquisition dates are: 10 May 2009, 11 May 2009, 18 May 2009 and 27 May 2009, so that, among these data, only one concerns the precipitation event. The images are right descending, with a mean incidence angle of $36^{\circ}$. They belong to the same satellite track, thus being useful for interferometric purposes, and have a geometric resolution of $2.2 \mathrm{~m}$ (both in slant range and azimuth).

The interferometric X-SAR complex coherence $\rho_{\text {coh }}$ feature between couples of X-SAR images has been exploited in order to investigate whether this kind of precipitation event could be detected by X-band SAR data. The complex coherence (or correlation) $\rho_{\text {coh }}$ is defined as (e.g., Burgmann et al., 2000):

$$
\begin{aligned}
& \rho_{\mathrm{coh}}(x, y)= \\
& =\frac{<s_{1}(x, y) s_{2}^{*}(x, y)>}{\sqrt{<s_{1}(x, y) s_{1}^{*}(x, y)><s_{2}(x, y) s_{2}^{*}(x, y)>}}
\end{aligned}
$$

where $s_{1}$ and $s_{2}$ are the corresponding complex pixel values, and the angle brackets indicate the expected value at the pixel of coordinates $(x, y)$, estimated by spatial averaging. The coherence $\rho_{\text {coh }}$ is mostly influenced by the phase difference between radar returns, a distinctive parameter measured by a coherent sensor, and is particularly related to the spatial arrangement of the scatterers within the pixel and thus to their possible displacements.

Zebker and Villasenor (1992) stated that the three main sources of SAR decorrelation are: spatial decorrelation (mostly related to the perpendicular baseline between acquisitions), thermal decorrelation and temporal decorrelation, which accounts for physical changes over the time period between two acquisitions. The temporal term is the subject we want to investigate in order to understand if the rain event causes changes in the interferometric coherence. Since it is not possible to estimate exactly the spatial and the thermal decorrelation, we can compute more than one interferogram trying to keep constant the contribution of the first two terms (spatial: same perpendicular baseline; thermal: same antenna). In this way it is possible to single out the temporal term by performing comparisons between the interferograms. Following this idea, three interferograms, which have perpendicular baselines spanning from 160 to $180 \mathrm{~m}$, have been computed, using the following couples of images: 10-11 May, 10-27 May and 11-18 May. Only the last interferogram includes the rain event.

The interferograms have been computed with a spatial resolution of about $\sim 23 \mathrm{~m}$, since a $10 \times 10$ multi-look processing was applied, in order to enhance the signal-to-noise ratio. After the topographic-phase removal, the coherence feature 

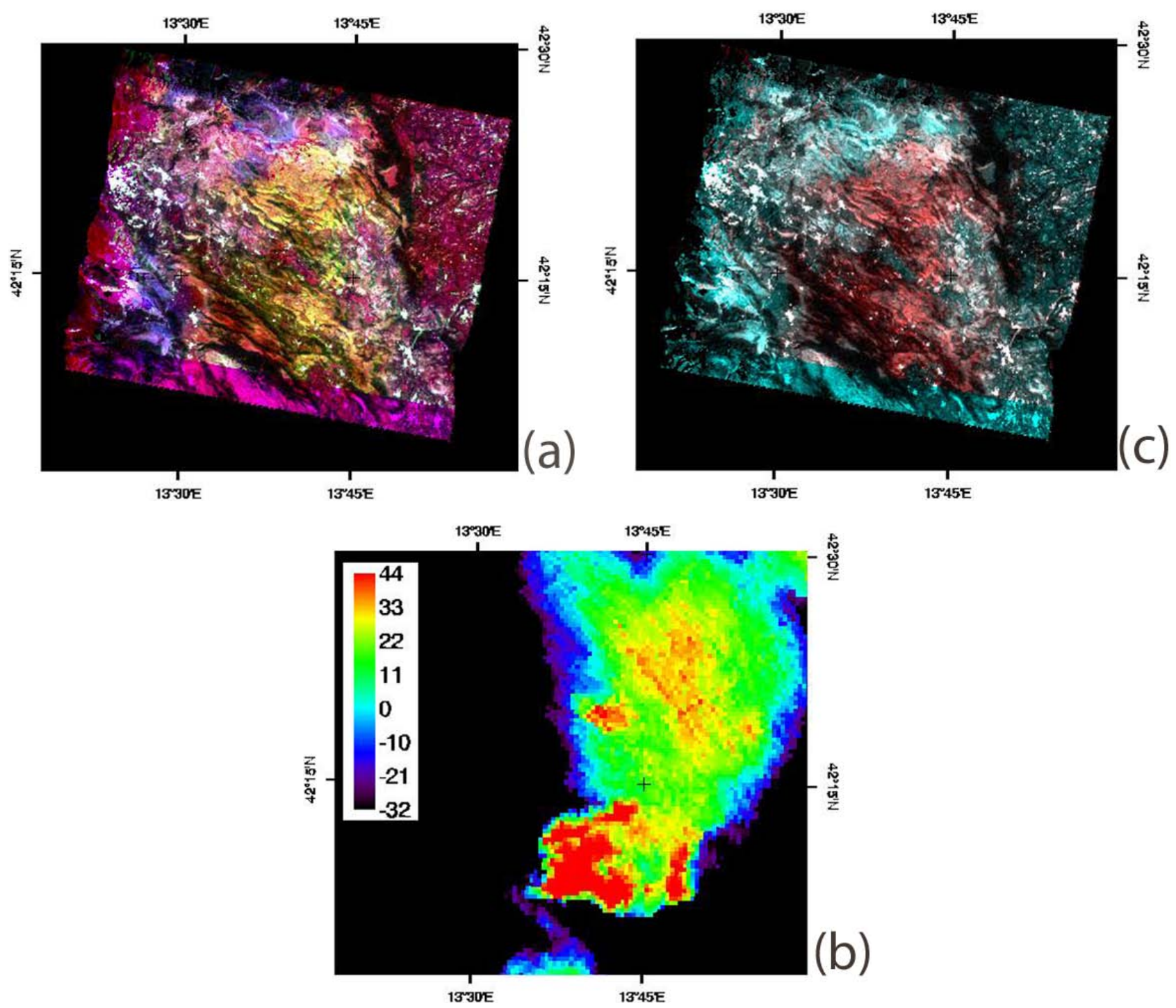

Fig. 6. Case study using CSK data over central Italy. (a) Three geocoded phase coherence images are shown in an RGB color composition: red $=c c_{10-11}$, Green $=c c_{10-27}$ and Blue $=c c_{11-18}$. (b) Precipitation map of the same area as observed by the C-band Mt. Midia weather radar in terms of reflectivity factor $Z(\mathrm{dBZ})$. (c) RGB composite of two geocoded phase coherence images $\left(\right.$ Red $=c c_{10}-27$, Green $=$ Blue $\left.=c c_{11-18}\right)$.

has been computed for each interferogram, using $5 \times 5$ pixels windows $(\sim 115 \times 115)$. The three geocoded phase coherence images, with a geometrical resolution of $130 \times 130 \mathrm{~m}^{2}$, are shown in Fig. 6a in an RGB color composition: 1011 May 2009 (Red, hereafter $c c_{10-11}$ ), 10-27 May 2009 (Green, hereafter $c c_{10-27)}$ and 11-18 May 2009 (Blue, hereafter $c c_{11-18}$ ). It is possible to see a yellow area (Red and Green are higher than Blue, i.e., the phase coherence is larger for the couples without rain), which is probably the area affected by rain on 18 May. In Fig. $6 \mathrm{~b}$ it is also shown the precipitation map of the same area as observed by the C-band Mt. Midia weather radar in terms of reflectivity factor $Z$. Note the maximum $Z$ of about $45 \mathrm{dBZ}$, much less than the values up to $59 \mathrm{dBZ}$ observed during the hurricane "Gustav" in Fig. 1. Such values indicate a relatively weak rain signature on X-SAR imagery, so that rain estimation with techniques similar to Eq. (4) can be affected by a fairly large uncertainty due to the surface backscattering variability, especially in presence of complex orography (see Marzano et al., 2010).

As expected, the $c c_{10-11}$ has an higher value, almost anywhere, with respect to $c c_{10-27}$ and $c c_{11-18}$, because it has only one day of temporal baseline. It is interesting to note that, in the region where we suppose the presence of rain effects (the red region in Fig. $6 c$; Red $=c c_{10-27}$, Green $=$ Blue $\left.=c c_{11-18}\right), c c_{10-27}$ has 
coherence values higher with respect to those of $c c_{11-18}$ including the rain event, despite the difference between the temporal baselines (ten days).

It is worth noting that the possible rain effect in Fig. 6a is eastward with respect to the detected rain in Fig. 6b, because of the geometric acquisition of the SAR satellite, which is right looking, descending orbit, with a looking angle of $36^{\circ}$ with respect to the vertical. The shift of the rain pattern is therefore perfectly coherent with the consideration that the pixels mostly affected by the rain event are those encountering more rain in the sensor-target path.

\section{Spatial variability of rainfall fields observed from space}

The potential of X-SAR high-resolution rain field retrieval may be qualitatively appreciated by spatially degrading TSX imagery taking into account the antenna pattern effect of the resolution-degraded sensor. Examples of inhomogeneous rain beam-filling can be also analyzed in terms of spatial variability of the rain fields. This section basically aims to show how not only the mean value, but also the whole statistics of the rain field is modified by the weighted spatial averaging due to the antenna beamwidth. This kind of analysis, even if it is not new (e.g., Harris et al., 2003), allows to appreciate the potential value of the spatial high-resolution of X-SAR space-based retrievals.

\subsection{Effect of spatial-resolution degradation}

In order to perform the analysis of spatial resolution impact, we have developed an ad hoc numerical simulator. The algorithm receives an input map, at a known spatial resolution (pixel), and spatially filters and down-samples it to an output map at a desired resolution. The spatial filter may be either a rectangular moving average or a Gaussian form with a box width or a standard deviation, respectively, related to the half-power beamwidth of the sensor field-of-view (FOV). We have applied this numerical simulator to TSX data to emulate what TRMM-PR and TRMM-TMI would have observed if those sensors had replaced the TSX antenna. These synthetic images have been indicated as PR-like and TMI-like products.

As already mentioned, the considered (linear) resolution for TSX and WR is about $0.5 \mathrm{~km}$, whereas that of PR-like and TMI-like are about 4 and $15 \mathrm{~km}$, respectively, the latter being considered as an approximation of the resolution of TMI channel at $37 \mathrm{GHz}$, selected as example of low-resolution data. WR data have been processed by down-sampling the rain-estimated image by a factor of 8 and 30, respectively, to yield PR-like and TMI-like results. Note that the subsequent discussion only regards the geometric consequences due to reduced resolution and antenna pattern, whereas the effects due to frequency-band difference are not considered (e.g., Marzano et al., 2002).

Precipitation is an intermittent non-linear field; this means that we have areas with zero values and others with strong horizontal gradient (see Fig. 7). When performing a convolution with a spatial discrete filter, such as that of the antenna beamwidth, the output is a field whose statistics is dependent on the filter-width and sampling strategy (Harris et al., 2003). Figure 7 shows the rain rate maps obtained by applying Eq. (3) to TSX, PR-like and TMI-like data; the WR rain rate map is obtained by Eq. (4). Some features of the PR-like and TMI-like images can be highlighted: (i) even if the reduced resolution leads to a loss of rain field details, the precipitation patterns are still quite congruent with the observed WR ones; (ii) the retrieved rain rate dynamics is quite dissimilar from the WR one as the antenna spatial integration tends to weaken rain peaks. The latter are significantly reduced: if for WR the maximum is $328.55 \mathrm{~mm} \mathrm{~h}^{-1}$, for TSX is $245.25 \mathrm{~mm} \mathrm{~h}^{-1}$, for PR-like is $111.64 \mathrm{~mm} \mathrm{~h}^{-1}$, and for TMI-like is $48.56 \mathrm{~mm} \mathrm{~h}^{-1}$; (iii) as expected, the sensitivity to lower rain rates decreases with the decreased spatial resolution, as shown by the WR precipitation front which tends to disappear within PR-like and TMI-like images.

The error statistics of rainfall estimates between WR, TSX, PR-like and TMI-like can be further analyzed and the main obtained statistical indexes are summarized in Table 2. The purpose of this analysis is to show the modification with resolution of the probability density of the estimated rain rate field and its correlation with the high-resolution spatial WR field as example of the possible advantages to exploit XSARbased retrievals. In this context the comparison has been carried out by, first comparing WR and TSX data at the same resolution (see Sect. 3.1) and then comparing PR-like/TMIlike data with the input TSX points. Note that the correlation parameter is about 0.68 for PR-like with respect to WR data and 0.48 for TMI-like with respect of respect WR points. The input PR-like rain with respect to TSX one has an error bias of $9.66 \mathrm{~mm} \mathrm{~h}^{-1}\left(-0.66 \mathrm{~mm} \mathrm{~h}^{-1}\right.$ of TSX versus WR), a standard deviation of $24.93 \mathrm{~mm} \mathrm{~h}^{-1}(22.27 \mathrm{~mm} \mathrm{h6}-1$ of TSX versus WR), a RMSE of $26.74 \mathrm{~mm} \mathrm{~h}^{-1}\left(22.38 \mathrm{~mm} \mathrm{~h}^{-1}\right.$ of TSX versus WR), a FRMSE of 0.81 (0.98 of TSX versus WR) and a correlation of 0.86 ( 0.75 of TSX versus WR). TMI-like rain has an error bias of $7.05 \mathrm{~mm} \mathrm{~h}^{-1}$, a standard deviation of $27.91 \mathrm{~mm} \mathrm{~h}^{-1}$, a RMSE of $28.79 \mathrm{~mm} \mathrm{~h}^{-1}$, a FRMSE of 0.87 and a correlation of 0.58 .

\subsection{Effects of non-uniform beam filling}

Beam filling is the error introduced when the field-ofview (FOV) of the spaceborne sensor is not filled with uniform rain and can lead to significant underestimation of rain rates (Harris et al., 2003). We can estimate the consequence of inhomogeneous beam filling on PR-like and TMI-like by choosing two sample pixels, the first one centered at about $31.38^{\circ} \mathrm{N} \times 89.33^{\circ} \mathrm{W}$, and the second one centered at about 
(a) WR-retrieved rain rate $(\mathrm{mm} / \mathrm{h})$

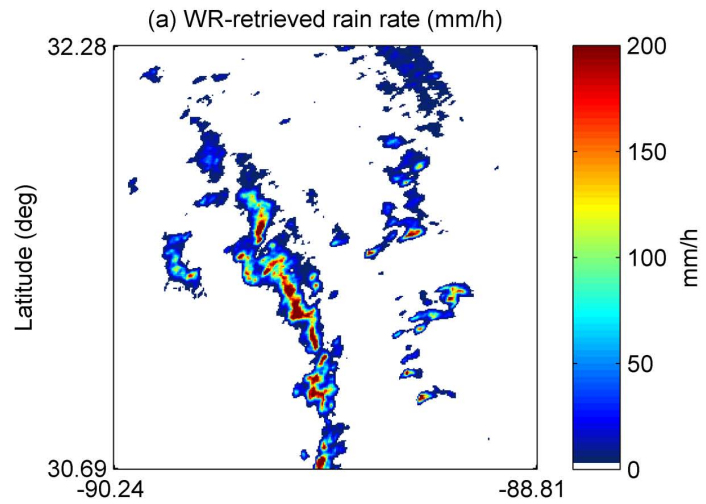

(c) PR-like-est. rain rate $(\mathrm{mm} / \mathrm{h})$

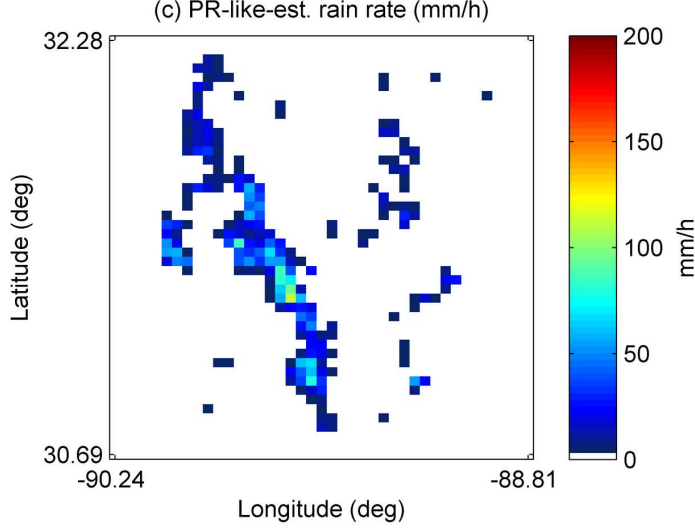

(b) TSX-estimated rain rate $(\mathrm{mm} / \mathrm{h})$

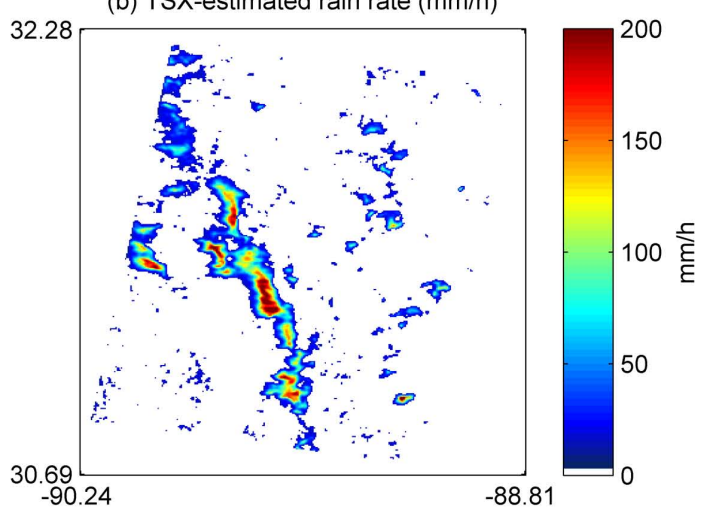

(d) TMI-like-est. rain rate $(\mathrm{mm} / \mathrm{h})$

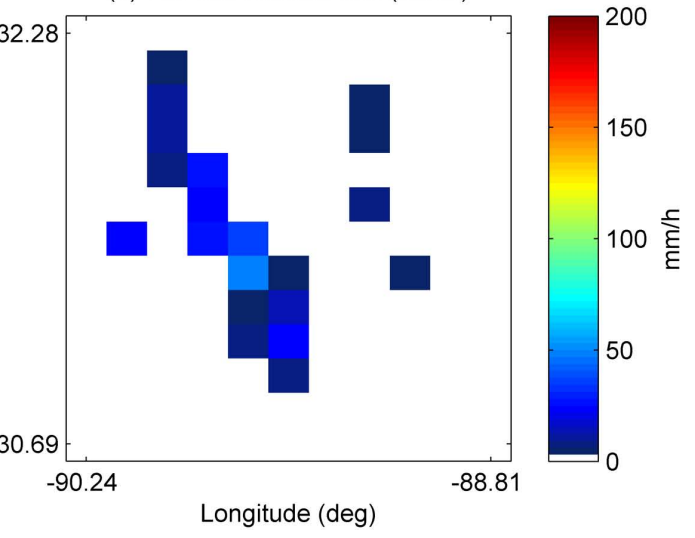

Fig. 7. Top left: map of measured rain rate $\left(\mathrm{mm} \mathrm{h}^{-1}\right)$ obtained by standard NEXRAD Z-R relation of Eq. (5) on the WR reflectivity for the case study in Fig. 1. Top right: map of TSX estimated rain rate $\left(\mathrm{mm} \mathrm{h}^{-1}\right)$ obtained by MREA technique in Eq. (4). Bottom left: map of PR-like estimated rain rate $\left(\mathrm{mm} \mathrm{h}^{-1}\right)$ obtained by Eq. (4). Bottom right: map of TMI-like estimated rain rate (mm $\left.\mathrm{h}^{-1}\right)$ obtained by Eq. (4). PR-like and TMI-like data are obtained by reducing resolution of the TSX data respectively at $4 \mathrm{~km} /$ pixel and $15 \mathrm{~km} /$ pixel and applying a Gaussian filter to emulate antenna pattern. TSX and WR input data are obtained from Fig. 4; note that for graphical purposes scales are equally saturated at $200 \mathrm{~mm} \mathrm{~h}^{-1}$, even though WR values can be higher than $300 \mathrm{~mm} \mathrm{~h}^{-1}$.

$31.00^{\circ} \mathrm{N} \times 89.96^{\circ} \mathrm{W}$. The first region is around the WR rain rate peak with a value of near $262 \mathrm{~mm} \mathrm{~h}^{-1}$, whereas the second pixel with WR rain-rate of near $1.6 \mathrm{~mm} \mathrm{~h}^{-1}$ is within a region corresponding to low rain rates of the Hurricane "Gustav" rain-band.

For the two regions above and around the chosen pixels, we have selected an area of $9 \times 9$ pixels and $31 \times 31$ pixels corresponding to the PR-like and TMI-like simulated fieldof-views (note that we are disregarding possible sampling mismatches among the various FOVs). For each area we have then derived the occurrence histogram of WR and TSX rain rates. The obtained results are shown in Figs. 8 and 9. In these figures both PR-like and TMI-like results are shown; all plots present a red bar corresponding to the PR-like or TMI-like pixel value, whereas a blue bar indicates the central pixel value of the plotted data series, computed within the corresponding FOV. Each plot series includes the histograms, computed within the corresponding FOV, of the TSX, TSX
Gaussian-filtered, WR and WR Gaussian-filtered data. TSX series have been included for clarity, to show the simulator input data and the numerical effect of the filter used to simulate antenna pattern. WR data shows the inhomogeneous beam filling of the simulated sensor cell, while WR filtered data shows the modifications on observed area rain dynamics introduced by antenna pattern.

Figure 8 is relative to the Hurricane "Gustav" rain peak area. The rain-rate for PR-like ranges from 70.71 to $282.61 \mathrm{~mm} \mathrm{~h}^{-1}$, whereas for TMI-like from 4.99 to $292.79 \mathrm{~mm} \mathrm{~h}^{-1}$. Within the TMI-like and PR-like FOVs, the "real" WR rain rate variability is fairly high (Fig. 8b and f). The broadening of the FOV leads to the inclusion of a lot of zero or very low rain rates which affects the whole histogram within the FOV itself. With respect to the "real" WR value, the maximum error (in absolute value) is $170.97 \mathrm{~mm} \mathrm{~h}^{-1}$ for PR-like and $244.21 \mathrm{~mm} \mathrm{~h}^{-1}$ for TMI-like. 

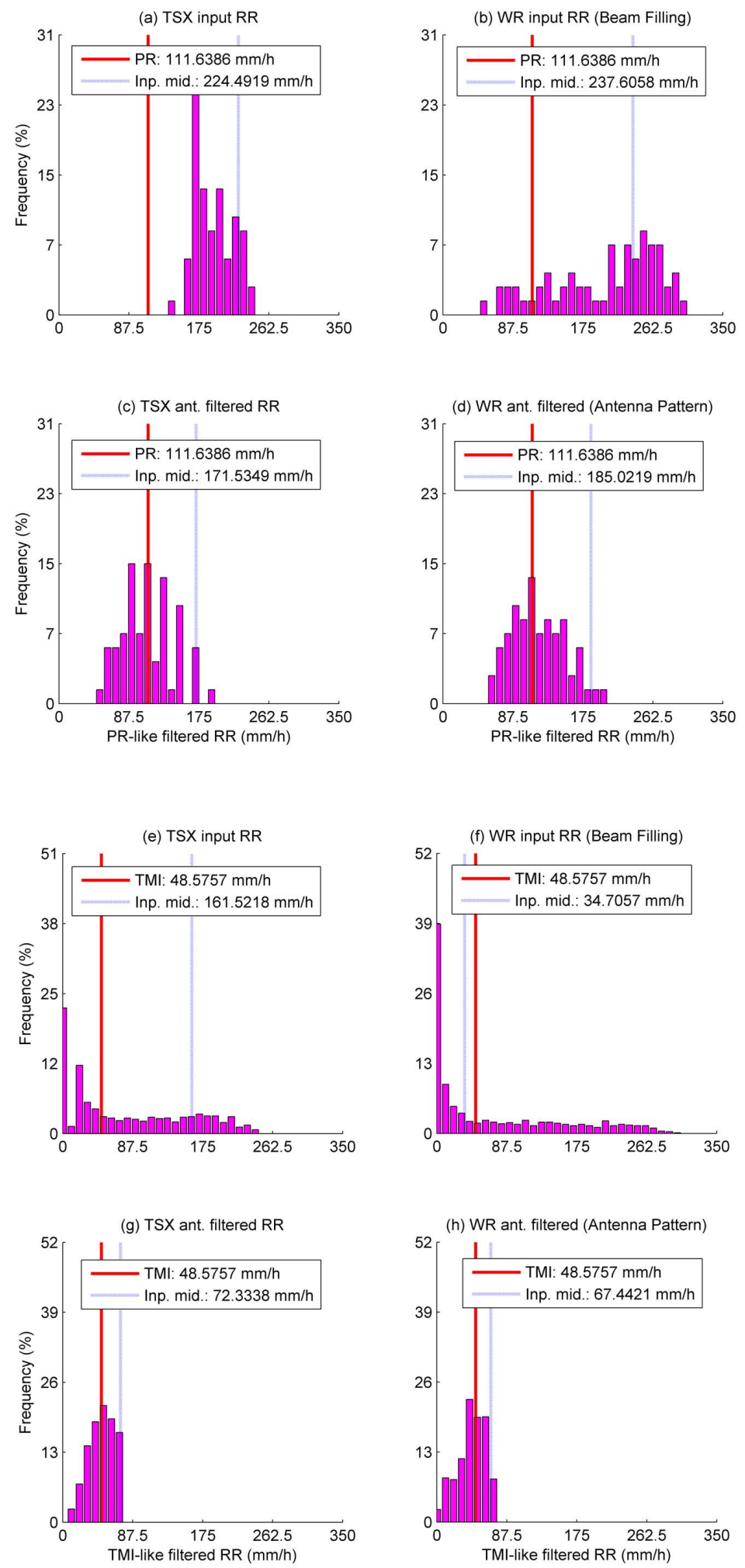

Fig. 8. Effects of the inhomogeneous beam filling and antenna pattern on PR-like (TSX spatial resolution reduced to that of PR) and TMIlike (TSX spatial resolution reduced to that of TMI) rain rate estimation within the pixel area centered at about $31.38^{\circ} \mathrm{N} \times 89.33^{\circ} \mathrm{W}$ (high precipitation area). The plots show the histogram of TSX (a, e) and WR $(\mathbf{b}, \mathbf{f})$ estimated rain rate $\left(\mathrm{mm} \mathrm{h}^{-1}\right)$ within the EFOV area, with bottom, (c, $\mathbf{g})$ for TSX and ( $\mathbf{d}, \mathbf{h})$ for WR - and without (top) the Gaussian filter which simulates the antenna pattern. The red bars represent the corresponding PR-like and TMI-like estimated rain rates $\left(\mathrm{mm} \mathrm{h}^{-1}\right)$, while the dotted blue line represent the TSX/WR value around the middle of simulated pixel. 

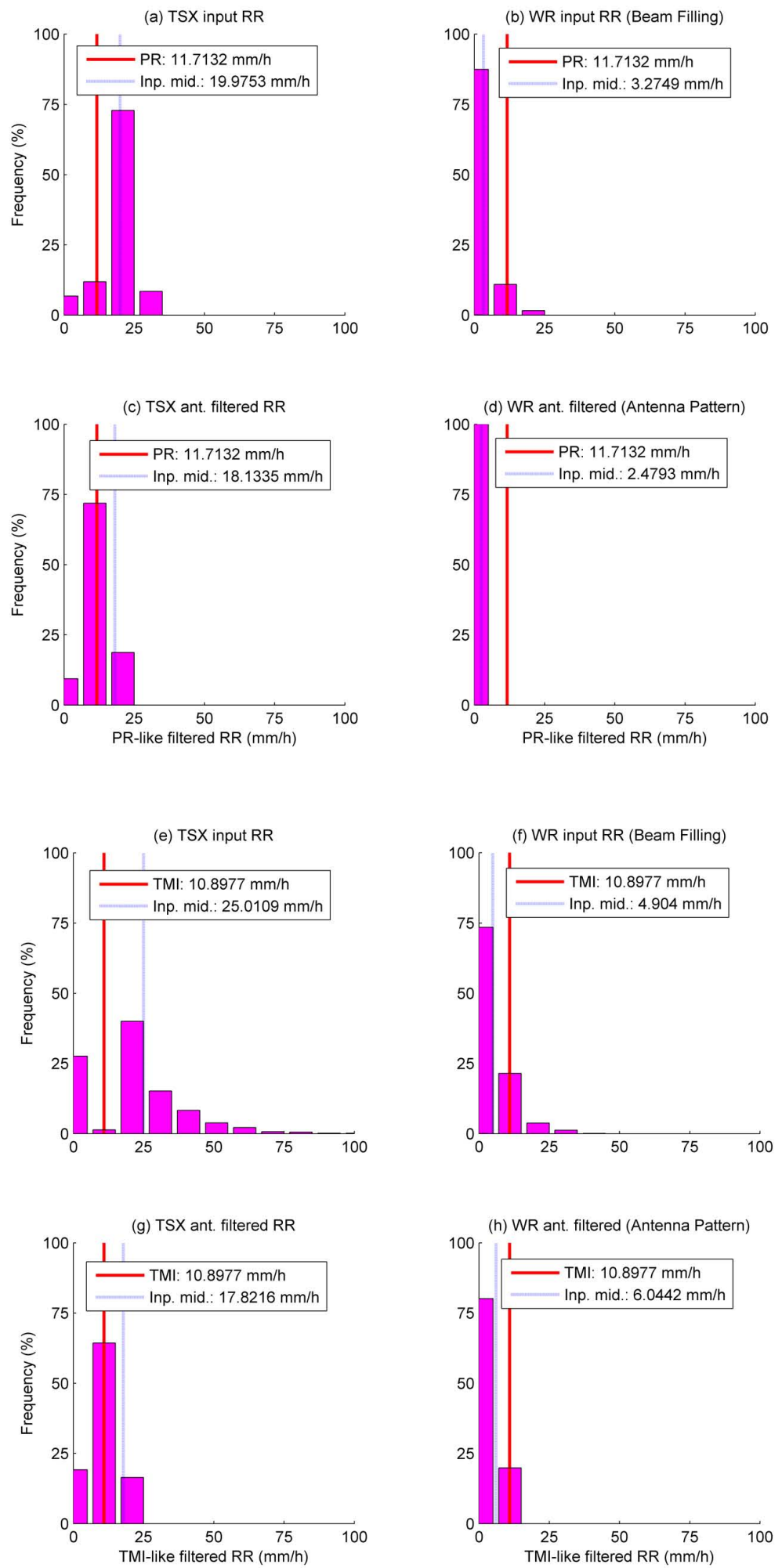

Fig. 9. Effects of the inhomogeneous beam filling and antenna pattern on PR-like and TMI-like rain rate estimation within the pixel area centered at about $31.00^{\circ} \mathrm{N} \times 89.96^{\circ} \mathrm{W}$ (low precipitation area). The plots show the histogram of TSX (a, e) and WR (b,f) estimated rain rate $\left(\mathrm{mm} \mathrm{h}^{-1}\right)$ within the EFOV area, with - bottom, (c, g) for TSX and (d, h) for WR - and without (top) the Gaussian filter which simulates the antenna pattern. The red bars represent the corresponding PR-like and TMI-like estimated rain rates $\left(\mathrm{mm} \mathrm{h}^{-1}\right)$, while the dotted blue line represents the TSX/WR value around the middle of simulated pixel. 
Table 2. Error analysis of the difference between the rain fields obtained at the spatial resolution of PR-like $(4 \mathrm{~km})$ and TMI-like $(15 \mathrm{~km})$ respect rain fields obtained at full resolution by TSX estimations and WR measurements. In brackets values of the WR - TSX rain rate difference. Error bias is respect TSX - degraded_simulation difference.

\begin{tabular}{|c|c|c|c|}
\hline & & \multicolumn{2}{|c|}{ Respect TSX } \\
\hline Error Bias $\left[\mathrm{mm} \mathrm{h}^{-1}\right]$ & $(-0.66)$ & 9.66 & 7.05 \\
\hline Dev. Standard & $(22.27)$ & 24.93 & 27.91 \\
\hline $\operatorname{RMSE}\left[\mathrm{mm} \mathrm{h}^{-1}\right]$ & $(22.28)$ & 26.74 & 28.79 \\
\hline FRMSE & $(0.98)$ & 0.81 & 0.87 \\
\hline \multirow[t]{2}{*}{ Correlation } & $(0.75)$ & 0.86 & 0.58 \\
\hline & & \multicolumn{2}{|c|}{ Respect WR } \\
\hline Correlation & $(0.75)$ & 0.68 & 0.48 \\
\hline
\end{tabular}

Another effect is due to sensor-antenna pattern which introduces a weighting (Gaussian) onto SAR retrieved data, modifying dynamic range (Fig. 8a,e and c,g): the TSX value of the pixel center before filtering is about $224.49 \mathrm{~mm} / \mathrm{h}$ for PR-like and $161.52 \mathrm{~mm} \mathrm{~h}^{-1}$ for TMI-like, while they are respectively $171.53 \mathrm{~mm} \mathrm{~h}^{-1}$ and $72.33 \mathrm{~mm} \mathrm{~h}^{-1}$ after filtering; the PR-like and TMI-like values obtained by the Gaussian filtering and a mean over the whole pixel area is $111.64 \mathrm{~mm} \mathrm{~h}^{-1}$ and $48.58 \mathrm{~mm} \mathrm{~h}^{-1}$ respectively. The effect of the antenna pattern filtering on the whole rain-rate histogram is shown in Fig. 8b,f and d,h. Top panels show the histogram of WR rain rates within the FOV area before the Gaussian filtering, whereas bottom ones show the histogram after the Gaussian filtering. The "observed" rain rate distribution is very different from the "real" one: this is particularly evident for the TMI-like histogram where all the non-rain pixels have almost disappeared. As numerical example, the WR value of the central pixel before filtering is about $237.61 \mathrm{~mm} \mathrm{~h}^{-1}$ for PR-like and $34.71 \mathrm{~mm} \mathrm{~h}^{-1}$ for TMI-like, while they are respectively $185.02 \mathrm{~mm} \mathrm{~h}^{-1}$ and $67.44 \mathrm{~mm} \mathrm{~h}^{-1}$ after filtering.

Similar conclusions can be derived from Fig. 9 relative to the low rain-rate area. The range of rain-rate values for PR-like is, in this case, from $1.23 \mathrm{~mm} \mathrm{~h}^{-1}$ to $16.35 \mathrm{~mm} \mathrm{~h}^{-1}$, whereas for TMI-like it is from $0.63 \mathrm{~mm} \mathrm{~h}^{-1}$ to $35.54 \mathrm{~mm} \mathrm{~h}^{-1}$. The maximum error (in absolute value) is $10.48 \mathrm{~mm} \mathrm{~h}^{-1}$ for PR-like and $24.64 \mathrm{~mm} \mathrm{~h}^{-1}$ for TMI-like. The retrieved rain rate, using the antenna pattern convolution, is $11.71 \mathrm{~mm} \mathrm{~h}^{-1}$ for PR-like and $10.90 \mathrm{~mm} \mathrm{~h}^{-1}$ for TMI-like, whereas the TSX and WR values of the central pixel at PRlike resolution are about $19.98 \mathrm{~mm} \mathrm{~h}^{-1}$ and $3.27 \mathrm{~mm} \mathrm{~h}^{-1}$ before filtering and $18.13 \mathrm{~mm} \mathrm{~h}^{-1}$ and $2.48 \mathrm{~mm} \mathrm{~h}^{-1}$ after; at TMI-like resolution they are $25.01 \mathrm{~mm} \mathrm{~h}^{-1}, 4.90 \mathrm{~mm} \mathrm{~h}^{-1}$, $17.82 \mathrm{~mm} \mathrm{~h}^{-1}$, and $6.04 \mathrm{~mm} \mathrm{~h}^{-1}$, respectively. It is worth stressing that these results have been obtained by a sensor simulator where a Gaussian filter has been applied to the pixel area without considering the antenna side-lobe effects.

\section{Conclusions}

The new generation of spaceborne X-SARs, which operate nowadays, may provide important opportunities to measure rainfall over land with a spatial resolution between few hundreds of meters and $1 \mathrm{~km}$, even though several issues must still be addressed and their quantitative use demonstrated. An analysis of two case studies, related to Hurricane "Gustav" on 2008 over Mississippi using co-registered WR and TSX X-SAR data and nearly contemporary TRMM ones, and to a Central Italy storm event observed by CSK in 2009, has shown: (i) a correlation between WR reflectivity measurements and X-SAR measured NRCS; (ii) a correlation between the X-SAR temporal coherence reduction and WR reflectivity field. Since SAR side-looking observation of precipitation tends to introduce a geometrical deformation of the retrieved field, we have also suggested a modified regressive empirical model to estimate rainfall rate from X-SAR whose comparison with WR estimates provides a RMSE less than $25 \mathrm{~mm} \mathrm{~h}^{-1}$ for hurricane torrential rainfall. Using numerical spatial filters to simulate the resolution of TRMM-PR and TRMM-TMI, it has been evaluated how spatial resolution affects in a significant way not only the covered area (providing an attribution error), but also the retrieved measurements and the sensitivity to lower rain rates, which are almost lost at lower resolutions.

The presented results are encouraging, even though more quantitative analyses are necessary regarding the effects of spatial resolution degradation and inhomogeneous beam filling of precipitation fields on physical hydrologic analyses. The suggested X-SAR rainfall retrieval algorithms need a systematic calibration and validation using several case studies. Further developments are foreseen toward more sophisticated inversion methodologies, whereas better comprehension of spaceborne observed precipitations can arise from the use of mesoscale cloud models coupled with SAR response model and from the polarimetric capability of spaceborne XSARs and ground-based WR sensors. The proposed technique of X-SAR rainfall algorithm calibration uses Weather Radar measurements. An appealing idea is to design a synergetic approach between X-SAR and geostationary weather satellites with the purpose to develop a fully spaceborne framework for X-SAR Earth observations. These issues need to be still investigated and will be the objective of future works. 


\section{Appendix A}

\section{Derivation of X-SAR modified regressive empirical algorithm}

The retrieved heavy rainfall, using the REA inversion formula given by Eq. (3), usually appears to be underestimated when applied to X-SAR data (see Marzano et al., 2010). Indeed, we may not be able to ignore the volume contribution to $\sigma_{\mathrm{SAR}}$ within heavy rainfall as well as the geometric deformation of X-SAR slant-view observation. Suppose that we can assume to have an infinitely wide rain cloud where the X-SAR NRCS is given by (e.g., Weinman and Marzano, 2008):

$\sigma_{\mathrm{SAR}}=\sigma^{0} e^{-2 k\left(z_{0} / \cos \theta\right)}+\frac{\eta \cos \theta}{2 k}\left[1-e^{-2 k\left(z_{0} / \cos \theta\right)}\right]$

where $k$ is specific attenuation, $\eta$ is the volumetric reflectivity, $z_{0}$ is freezing level, $\theta$ the incident angle. We can rewrite Eq. (A1) as:

$\sigma_{\mathrm{SAR}}=\sigma^{0} e^{-2 k\left(z_{0} / \cos \theta\right)}\left[1+\frac{\eta \cos \theta}{2 k \sigma^{0}}\left(e^{2 k\left(z_{0} / \cos \theta\right)}-1\right)\right]$

Taking the natural logarithm of Eq. (A2), we get:

$$
\begin{aligned}
\ln \sigma_{\mathrm{SAR}} & =\ln \sigma^{0}-2 k\left(z_{0} / \cos \theta\right) \\
& +\ln \left[1+\frac{\eta \cos \theta}{2 k \sigma^{0}}\left(e^{2 k\left(z_{0} / \cos \theta\right)}-1\right)\right]
\end{aligned}
$$

By also defining:

$\Delta \sigma_{\mathrm{SAR}}=\ln \sigma^{0}-\ln \sigma_{\mathrm{SAR}}=\Delta \sigma_{\mathrm{SAR}} \mathrm{dB} / 4.343$

and approximating:

$\ln \left[1+\frac{\eta \cos \theta}{2 k \sigma^{0}}\left(e^{2 k\left(z_{0} / \cos \theta\right)}-1\right)\right] \approx \frac{\eta z_{0}}{\sigma^{0}}$

we obtain:

$\Delta \sigma_{\mathrm{SAR}}=2 k z_{0} / \cos \theta-\eta z_{0} / \sigma^{0}$

By posing $k=a R^{\mathrm{b}}$ and $\eta=c R^{\mathrm{d}}$ (Weinman and Marzano, 2008), we can write:

$\Delta \sigma_{\mathrm{SAR}}=A R^{\mathrm{b}}-B R^{\mathrm{d}}$

where $A$ and $B$ are two proper coefficients, derived from Eq. (A6) or from empirical least-square analysis. The previous equation can be further approximated at first-order by using Eq. (3) into the volumetric term to yield:

$\Delta \sigma_{\mathrm{SAR}} \cong A R^{\mathrm{b}}-B\left[a_{\mathrm{e}}\left(4.343 \Delta \sigma_{\mathrm{SAR}}\right)^{b_{\mathrm{e}}}\right]^{\mathrm{d}}$

By inverting Eq. (A8), the rainfall inversion model may be expressed by:

$\hat{R} \cong\left[\frac{\Delta \sigma_{\mathrm{SAR}}+B\left[a_{\mathrm{e}}\left(4.343 \Delta \sigma_{\mathrm{SAR}}\right)^{b_{\mathrm{e}}}\right]^{\mathrm{d}}}{A}\right]^{1 / \mathrm{b}}$
Note that setting $B=0$ in Eq. (A9) gives a form that is the same as Eq. (3), but including the second term increases the large $R$ values for a given $\Delta \sigma_{\mathrm{SAR}}$. Finally, in order to mitigate the geometrical error due to the X-SAR cross-track slant view, we can introduce an empirical geometrical factor $f_{\mathrm{G}}$, expressed by:

$f_{\mathrm{G}}(x)=\left\{\begin{array}{l}{\left[1 /\left(x-x_{0}\right)\right]^{c_{\mathrm{e}}} x_{0}+\varepsilon \leq x \leq x_{0}+w} \\ 0 \text { otherwise }\end{array}\right.$

where $w$ is the cross-track cell width $(\mathrm{km})$ and $x_{0}$ the point where the incident SAR ray begins to intersect the cell (see Marzano and Weinman, 2008; Marzano et al., 2010). The small increment $\varepsilon$ in Eq. (A10) is introduced to prevent the geometrical factor $f_{\mathrm{G}}(x)$ in Eq. (A10) from becoming infinite. This means that the final modified regressive empirical algorithm (MREA) can be rearranged as follows:

$\hat{R}_{\mathrm{MREA}}(x)=\left[\frac{\Delta \sigma_{\mathrm{SARdB}}(x)+b_{\mathrm{v}} \Delta \sigma_{\mathrm{SARdB}}^{c_{\mathrm{v}}}(x)}{a}\right]^{1 / \mathrm{b}} f_{\mathrm{G}}(x)$

where the parameters $a, b, b_{\mathrm{v}}, c_{\mathrm{v}}$ and $c_{\mathrm{e}}$ are unknown coefficients to be derived from an empirical regression analysis. The Eq. (A11) justifies the retrieval statistical parametric model, proposed in Eq. (4).

Acknowledgements. The authors would like to thank E. Picciotti (Italy), A. Roth and S. Lehner (DLR, Germany) for their cooperation and the helpful discussions. We also acknowledge the TSX Science Team for providing the TSX MGD data under the "AtmoX" project and the CSK Science Team for providing CSK data under the "RainXSAR" project. NCDC-NOAA is gratefully acknowledged for providing NEXRAD weather radar data and software tools (www.ncdc.noaa.gov/oa/wct), NASA GES-DISC, U. S. for providing TRMM data and tools (disc.sci.gsfc.nasa.gov), Regione Abruzzo (Italy) for providing C-band Mt. Midia radar data. This work has been partially supported by the National Department of Civil Protection, Rome (Italy) and by Region Abruzzo (Italy).

Edited by: Prof. Bob Su

\section{References}

Atlas, D. and Moore, R. K.: The measurement of precipitation with synthetic aperture radar, J. Atmos. Ocean. Tech., 4, 368-376, 1987.

Bennartz, R. and Petty, G. W.: The sensitivity of microwave remote sensing observations of precipitation to ice particle size distributions, J. Appl. Meteorol., 40, 345-364, 2001.

Buckreuss, S., Balzer, W., Muhlbauer, P., Werninghaus, R., and Pitz, W.: The TerraSAR-X satellite project, Proc. IGARSS, 5, 3096-3098, 2003.

Burgmann, R., Rosen, P. A., and Fielding, E. J.: Synthetic aperture radar interferometry to measure Earth's surface topography and its deformation, Annu. Rev. Earth Planet. Sc., 28, 169-209, 2000. 
Chandrasekar, V. and Fritz, J.: Simultaneous observations of Xband polarimetric SAR and ground-based weather radar during a tropical storm to characterise the propagation effects, Proc. EUCAP, Berlin, Germany, 23-27 March, 2009.

Coletta, A., Angino, G., Battazza, F., Caltagirone, F., Impagnatiello, F., Valentini, G., Capuzi, A., Fagioli, S., and Leonardi, R.: COSMO-SkyMed program: Utilization and description of an advanced space EO dual-use asset, Proc. Envisat Symp., 2327 April 2007, ESA SP-636, Montreux, Switzerland, 2007.

Covello, F., Battazza, F., Coletta, A., Lopinto, E., Fiorentino, C., Pietranera, L., Valentini, G., and Zoffoli, S.: COSMO-SkyMed an existing opportunity for observing the Earth, J. Geodynam., 49, 171-180, 2010.

Danklmayer, A., Doring, B. J., Schwerdt, M., and Chandra, M.: Assessment of Atmospheric Propagation Effects in SAR Images, IEEE T. Geosci. Remote, 47, 112-132, 2009.

Dingman, S. L.: Physical Hydrology, 2nd Edition Prentice-Hall, Inc., 113 Sylvan Ave., Englewood Cliffs, NJ, USA, 656 pp., 2002.

Durden, S. L., Haddad, Z. S., Kitiyakara, A., and Li, F. K.: Effects of non-uniform beam filling on rainfall retrieval for the TRMM Precipitation Radar, J. Atmos. Ocean. Tech., 15, 635-646, 1998.

Fulton, R. A., Breidenbach, J. P., Seo, D.-J., Miller, D. A., and O'Bannon, T.: The WSR-88d Rainfall Algorithm, Weather Forecast., 13, 377-395, 1998.

Harris, D., Foufoula-Georgiou, E., and Kummerow, C.: Effects of underrepresented hydrometeor variability and partial beam filling on microwave brightness temperatures for rainfall retrieval, J. Geophys. Res., 108(D8), 8380, doi:10.1029/2001JD001144, 2003.

Iguchi, T., Kozu, T., Meneghini, R., Awaka, J., and Okamoto, K.: Rain profiling algorithm for the TRMM Precipitation Radar, J. Appl. Meteorol., 39, 2038-2052, 2000.

Jameson, A. R., Li, F., Durden, S. L., Haddad, Z. S., Holt, B., Fogary, T., Im, E., and Moore, R. K.: SIR-C/X-SAR observations of rainstorms, Remote Sens. Environ., 59, 267-279, 1997.

Kummerow, C., Barnes, W., Kozu, T., Shiue, J., and Simpson, J.: The Tropical Rainfall Measuring Mission (TRMM) Sensor Package, J. Atmos. Ocean. Tech., 15, 809-817, 1998.

Marzano, F. S. and Weinman, J. A.: Inversion of spaceborne X-band synthetic aperture radar measurements for precipitation remote sensing over land, IEEE T. Geosci. Remote., 46, 3472-3487, 2008.

Marzano, F. S., Mugnai, A., and Turk, F. J.: Precipitation retrieval from spaceborne microwave radiometers and combined sensors, in: Remote Sensing of Atmosphere and Ocean From Space: Models, Instruments and Techniques, edited by: Marzano, F. S. and Visconti, G., Kluwer, Dordrecht, The Netherlands, 107-126, 2002.

Marzano, F. S., Scaranari, D., Vulpiani, G., and Montopoli, M.: Supervised classification and estimation of hydrometeors using C-band dual-polarized radars: a Bayesian approach, IEEE T. Geosci. Remote, 46, 85-98, 2008.
Marzano, F. S., Mori, S., Pierdicca, N., Pulvirenti, L., and Weinman, J. A.: Characterization of atmospheric precipitation effects on spaceborne synthetic aperture radar response at $\mathrm{X}, \mathrm{Ku}, \mathrm{Ka}$ band, Ital. J. Remote Sens., 41, 73-88, 2009.

Marzano, F. S., Mori, S., and Weinman, J. A:, Evidence of Rainfall Signatures on X-Band Synthetic Aperture Radar Imagery Over Land, IEEE T. Geosci. Remote, 48, 950-964, 2010.

Massonnet, D. and Feigl, K. L.: Radar interferometry and its application to changes in the Earth's surface, Rev. Geophys., 36, 441-500, 1998.

Masunaga, H., Satoh, M., and Miura, H.: A joint satellite and global cloud-resolving model analysis of a Madden-Julian Oscillation event: Model diagnosis, J. Geophys. Res., 113, D17210, doi:10.1029/2008JD009986, 2008.

Matricciani, E.: A Relationship Between Phase Delay and Attenuation Due to Rain and Its Applications to Satellite and Deep-Space Tracking, IEEE T. Antenn. Propag., 57, 3602-3611, 2009.

Melsheimer, C., Gade, M., and Alpers, W.: Investigation of multifrequency/multipolarization radar signatures of rain cells derived from SIR-C/X-SAR data, J. Geophys. Res., 103, 18867-18884, 1998.

Moisseev, D. and Hanssen, R.: Influence of hydrometeors on InSAR observations, in: Proc. of Geoscience and Remote Sensing Symposium, July 2003, IGARSS 2003, 6(21-25), 3811-3814, 2003.

Picciotti, E., Gallese, B., Cimoroni, A., Montopoli, M., Telleschi, A., Volpi, A., Consalvi, F. and Marzano, F. S.: C-band radar precipitation measurements in mountainous region: comparison with raingauge fields and X-band radar data, Proceeding of the 5th European conference on radar in meteorology and hydrology ERAD 2008, 30 June-4 July 2008, Helsinki, Finland, 2008.

Quegan, S. and Lamont, J.: Ionospheric and tropospheric effects on synthetic aperture radar performance, Int. J. Remote Sens., 7, 525-539, 1986.

Ryzhkov, A., Giangrande, S. E., and Schuur, T. J.: Rainfall estimation with a polarimetric prototype of WSR-88D, J. Appl. Meteorol., 44, 502-515, 2005.

Solheim, F. S., Vivekanandan, J., Ware, R., and Rocken, C.: Propagation delays induced in GPS signals by dry air, water vapor, hydrometeors, and other particulates, J. Geophys. Res.-Atmos., 104(D8), 9663-9670, 1999.

Tapiador, F. J., Kidd, C., Levizzani, V., and Marzano, F. S.: A neural networks-based PMW-IR fusion technique to derive half hourly rainfall estimates at $0.1^{\circ}$ resolution, J. Appl. Meteorol., 43, 576594, 2004.

Weinman, J. A. and Marzano, F. S.: An exploratory study to derive rainfall over land from spaceborne synthetic aperture radars, J. Appl. Meteorol. Clim., 47, 562-575, 2008.

Weinman, J. A., Marzano, F. S., Plant, W. J., Mugnai, A., and Pierdicca, N.: Rainfall observation from X-band, space-borne, synthetic aperture radar, Nat. Hazards Earth Syst. Sci., 9, 77-84, doi:10.5194/nhess-9-77-2009, 2009.

Zebker, H. A. and Villasenor, J.: Decorrelation in interferometric radar echoes, IEEE T. Geosci. Remote, 30, 950-959, 1992. 